\title{
Enhancement of glucosinolate and isothiocyanate profiles in brassicaceae crops: addressing challenges in breeding for cultivation, storage, and consumer- related traits
}

Article

Accepted Version

Bell, L. and Wagstaff, C. (2017) Enhancement of glucosinolate and isothiocyanate profiles in brassicaceae crops: addressing challenges in breeding for cultivation, storage, and consumerrelated traits. Journal of Agricultural and Food Chemistry, 65 (43). pp. 9379-9403. ISSN 1520-5118 doi:

https://doi.org/10.1021/acs.jafc.7b03628 Available at https://centaur.reading.ac.uk/73332/

It is advisable to refer to the publisher's version if you intend to cite from the work. See Guidance on citing.

Published version at: http://dx.doi.org/10.1021/acs.jafc.7b03628

To link to this article DOI: http://dx.doi.org/10.1021/acs.jafc.7b03628

Publisher: American Chemical Society

All outputs in CentAUR are protected by Intellectual Property Rights law, including copyright law. Copyright and IPR is retained by the creators or other copyright holders. Terms and conditions for use of this material are defined in the End User Agreement. 


\section{www.reading.ac.uk/centaur}

\section{CentAUR}

Central Archive at the University of Reading

Reading's research outputs online 
Enhancement Of Glucosinolate \& Isothiocyanate Profiles In Brassicaceae Crops: Addressing Challenges In Breeding For Cultivation, Storage, and Consumer Related Traits

Luke Bell ${ }^{1}$ \& Carol Wagstaff ${ }^{1}$

${ }^{1}$ Department of Food \& Nutritional Sciences, University of Reading, Whiteknights, Reading, Berkshire. RG6 6AP, UK 


\section{ABSTRACT}

Glucosinolates (GSLs) and isothiocyanates (ITCs) produced by Brassicaceae plants

3 are popular targets for analysis due to the health benefits associated with them. Breeders aim

4 to increase the concentrations in commercial varieties, however there are few examples of 5 this. The most well known is Beneforté broccoli, which has increased 6 glucoraphanin/sulforaphane concentrations compared to conventional varieties. It was 7 developed through traditional breeding methods with considerations for processing, 8 consumption and health made throughout this process. Many studies presented in the 9 literature do not take a holistic approach, and key points about breeding, cultivation methods, 10 postharvest storage, sensory attributes and consumer preferences are not properly taken into 11 account. In this review, we draw together data for multiple species and address how such 12 factors can influence GSL profiles. We encourage researchers and institutions to engage with 13 industry and consumers to produce research that can be utilised in the improvement of 14 Brassicaceae crops.

16 Keywords: Brassica, Phytochemicals, Plant breeding, Nutrition, Processing, 17 Chemoprotection, Glucoraphanin, Indoles, Broccoli, Cabbage, Mustards 


\section{INTRODUCTION}

Crops of the Brassicaceae family contain numerous phytochemicals that are known,

28 or are suspected to be, beneficial for human health. These include sulfur-containing 29 glucosinolates (GSLs) ${ }^{1}$, which have a range of hydrolysis products that are noted for 30 beneficial effects on human health ${ }^{2}$. GSLs are secondary metabolites that are hydrolysed by 31 myrosinases and modified by specifier proteins into numerous breakdown products ${ }^{3}$; these include isothiocyanates (ITCs), thiocyanates, nitriles, ascorbigens, indoles, oxazolidine-2-

33 thiones and epithioalkanes ${ }^{4}$. This process is part of a complex defense strategy utilised by

34 Brassicaceae plants to protect against herbivory, pests and diseases ${ }^{5}$. These compounds also 35 give the family their distinctive sulphurous, hot, mustard and pepper flavors ${ }^{6}$.

36 Potential health benefits such as anti-carcinogenic and anti-metastatic activity have 37 been linked with these compounds (such as ITCs and indoles) in cell and animal studies ${ }^{7}$. 38 Clinical, epidemiological and pharmacological research in humans has demonstrated 39 beneficial effects in vivo on some cancers, on cardiovascular health ${ }^{8,9}$, and on 40 neurodegenerative prevention ${ }^{10}$. For these reasons, there is huge interest in enhancing 41 Brassicaceae crop GSL content ${ }^{11}$. Despite initiatives such as the "5-a-day" campaign, fruit and veg consumption remains low in Western countries, and chronic diseases such as cancer and cardiovascular disease are leading to premature deaths ${ }^{12}$.

This review will explore prominent species and some underutilised edible

45 Brassicaceae crops with the potential for GSL/ITC profile improvement. The health benefits 46 that have been linked to these compounds and how they can be maximized will also be 47 discussed. We aim to highlight and explore the challenges faced in developing enhanced 48 Brassicaceae varieties in three key areas: plant breeding, agronomic practice, and 'the consumer'. Previous review papers have not directly addressed the discrepancies between

50 scientific research methods and common agricultural and commercial practices, or how plant 
51 breeders can use scientific findings to inform their selections. Our goal is not to define the

52 ideal crop for enhancement, but to highlight species that require further study and

53 development. We encourage research groups to consider the entire commercial supply chain,

54 and how this affects plant phytochemistry in a 'real world' context. We also highlight the

55 need for consideration of the sensory preferences and end consumer metabolic genotypes. In

56 this way, commercial breeders/producers can utilise better scientific research to improve crop

57 nutritional density, and make informed decisions about varietal selection and agronomic

58 practice.

59

60 BRASSICACEAE CROPS \& GLUCOSINOLATE PROFILES

\section{General}

Table 1 summarises and compares the GSL profiles of several major, minor and underutilised Brassicaceae crops, and gives examples of typical concentrations that have been

64 reported within the scientific literature. The following section describes these profiles and 65 illustrates how concentrations and profiles vary between species.

66 Broccoli (Brassica oleracea var. italica)

Perhaps the most well studied Brassicaceae crop is broccoli ${ }^{13}$. It is a well-known vegetable that is grown and consumed worldwide, and production rates are increasing ${ }^{14}$. The

69 key factor in its popularity from a research perspective is that it contains significant 70 glucoraphanin concentrations in florets and sprouts (Table 1) ${ }^{11,14-34}$. Total reported 71 concentrations in broccoli florets are modest $\left(\sim 7.9 \mathrm{mg} \cdot \mathrm{g}^{-1} \mathrm{dw}\right.$, Table 1$)$ compared to other 72 commonly consumed crops such as Brussels sprouts $\left(\sim 13.3 \mathrm{mg} \cdot \mathrm{g}^{-1} \mathrm{dw}\right)$. That being said, 73 some varieties have high total concentrations $\left(26.9 \mathrm{mg} \cdot \mathrm{g}^{-1} \mathrm{dw}{ }^{16}\right)$, well in excess of the 74 average.

75 Brussels Sprouts (Brassica oleracea var. gemmifera) 
Although broccoli and kale are most often ascribed with the most potent health

77 benefits associated with GSLs, Brussels sprouts have higher total concentrations than both, 78 on average $\left(\sim 13.3 \mathrm{mg} \cdot \mathrm{g}^{-1} \mathrm{dw}\right)$. Although not containing high levels of glucoraphanin, sprouts 79 do have high amounts of glucobrassicin (Table 1) $18,19,25,31,32,34,35$.

80 Cabbage, Red Cabbage, \& White Cabbage (Brassica oleracea var. capitata, Brassica oleracea var. capitata f. rubra, \& Brassica oleracea var. capitata f. alba) concentrations compared to other crops (Table 1) ${ }^{1,25,31,32,36,37}$. White cabbage is similar to the green variety in terms of its overall GSL profile ${ }^{31,32,38}$.

Red cabbage contains similar GSLs to white and green cabbages, but differs in the relative amounts present within leaf tissues; e.g. it contains greater concentrations of 87 glucoraphanin and gluconapin, and less sinigrin ${ }^{1,31,32,39-41}$. Overall, average reported concentrations are higher in red cabbages than other types.

\section{Cauliflower (Brassica oleracea var. botrytis)}

Total GSL reports in cauliflower florets range from $0.7-11.4 \mathrm{mg} \cdot \mathrm{g}^{-1} \mathrm{dw}$, but average $91 \sim 4.1 \mathrm{mg} \cdot \mathrm{g}^{-1} \mathrm{dw}$; much lower than broccoli and Brussels sprouts. The predominant major GSL 92 reported is glucobrassicin $\left(\sim 1.7 \mathrm{mg}^{\left.-\mathrm{g}^{-1} \mathrm{dw}\right)}\right)^{18,19,21,22,25,31,32,34,42}$.

\section{Chinese Cabbage (Brassica rapa var. chinensis \& Brassica rapa var. pekinensis)}

There are two predominant Chinese cabbage varieties: B. oleracea var. pekinensis and

95 B. oleracea var. chinensis. These crops originate and are popular in China and southeast 96 Asia, and have been identified as candidates for GSL accumulation trait improvement 97 through breeding, due to large phenotypic variation ${ }^{43,44}$. Total average GSL contents 98 reported are modest compared to other crops (Table 1). Indolic GSLs make up a large 99 proportion of the overall profile ${ }^{31,32,36,43-45}$.

100 Chinese Kale (Brassica oleracea var. alboglabra) 
102 but not well known in other parts of the world. It is noted for high GSL concentrations

103 (compared with broccoli florets). Total concentrations in mature leaves have been reported to

104 be $14.9 \mathrm{mg} \cdot \mathrm{g}^{-1} \mathrm{dw}{ }^{21}$ (broccoli florets: $7.9 \mathrm{mg} \cdot \mathrm{g}^{-1} \mathrm{dw}$ ). In sprouts, GSL concentrations have

105 been reported as high as $98.2 \mathrm{mg} \cdot \mathrm{g}^{-1} \mathrm{dw}{ }^{46}$ and as low as $3.7 \mathrm{mg} \cdot \mathrm{g}^{-1} \mathrm{dw}{ }^{47}$.

\section{Collards (Brassica oleracea var. sabellica)}

107 Collards are an understudied variety of $B$. oleracea, but have high total GSL 108 concentrations $\left(18.2 \mathrm{mg} \cdot \mathrm{g}^{-1} \mathrm{dw}\right)$. Sinigrin concentrations $\left(6.5 \mathrm{mg} \cdot \mathrm{g}^{-1} \mathrm{dw}\right)$, glucobrassicin $(4.6$ $\left.109 \mathrm{mg} \cdot \mathrm{g}^{-1} \mathrm{dw}\right)$, progoitrin $\left(2.9 \mathrm{mg} \cdot \mathrm{g}^{-1} \mathrm{dw}\right)$ and glucoiberin $\left(1.0 \mathrm{mg} \cdot \mathrm{g}^{-1} \mathrm{dw}\right)$ make up the typical 110 profile ${ }^{18,19}$.

\section{Ethiopian mustard (Brassica carinata)}

112 Ethiopian mustard is a traditional leafy crop of Africa and contains modest GSL 113 concentrations. These include minor amounts of glucoalyssin, gluconapin, progoitrin, 114 glucobrassicin, 4-hydroxyglucobrassicin, 4-methoxyglucobrassicin, neoglucobrassicin and 115 gluconasturtiin, with the vast majority composed of sinigrin (Table 1) ${ }^{48}$. The crop is 116 underutilised in terms of breeding and could be developed to a higher quality, both for human 117 consumption and as a potential biofumigant crop ${ }^{49}$.

\section{Ezo-wasabi (Cardamine fauriei)}

119 Ezo-wasabi is a niche herb crop that originates from Hokkaido, Japan. It is a popular 120 herb in this region and is characterised by a pungent wasabi-like flavor due to very high GSL 121 concentrations. Abe et al. ${ }^{50}$ identified three GSL compounds within leaves: glucoiberin, 122 gluconapin and glucobrassicin. Total concentrations were reported to average $63.0 \mathrm{mg} \cdot \mathrm{g}^{-1} \mathrm{dw}$.

\section{Kale (Brassica oleracea var. acephala)}

124 Kale has been reported as having a wide range of health benefits, including those 125 associated with GSLs ${ }^{51}$. Total concentrations are generally modest ${ }^{18,19,25,37,52}$, but some 
126 studies report concentrations higher than broccoli. A comprehensive analysis of 153 field-

127 grown cultivars by Cartea et al. ${ }^{37}$, found the average concentrations to be higher at 10.7

$128 \mathrm{mg} \cdot \mathrm{g}^{-1} \mathrm{dw}$. The profile consists of predominantly aliphatic GSLs: with some aromatic and

129 indole compounds present. The concentrations of the latter are reported as being highest, on 130 average.

\section{Kohlrabi (Brassica oleracea var. gongylodes)}

Kohlrabi stems are low in GSLs with average concentrations amounting to $\sim 2.2 \mathrm{mg} . \mathrm{g}^{-}$

$133{ }^{1} \mathrm{dw}$. The profile is composed of glucoiberin, glucoraphanin, glucoalyssin, glucoiberverin, 134 glucoerucin, glucobrassicin, gluconasturtiin, and neoglucobrassicin, with some other trace 135 GSLs identified ${ }^{18,19,31,32}$.

\section{Leaf rape \& Turnip rape (Brassica napus var. pabularia \& Brassica napus)} Rapeseed leaves contain modest GSL amounts, but like collards are not widely

138 consumed by the public. The bulk of the leaf rape GSL profile is made up of 139 glucobrassicanapin, progoitrin and gluconapin ${ }^{53}$. Turnip rape by contrast is composed 140 predominantly of gluconapin ${ }^{36}$. Sprouts have relatively high GSL abundances compared to 141 the mature leaf tissue (Table 1) ${ }^{11}$.

142 Maca (Lepidium meyenii)

143 Maca roots are not commonly consumed in western diets, but are prominent in South 144 American cuisine. Three main cultivar forms are consumed (red, purple, and black) and 145 powders are popular as "food supplements" with anecdotal health benefits attributed to them.

146 The species is an ideal candidate for improvement efforts, as it contains a wide variety of 147 traits and compounds with purported health benefits, such as phytosterols ${ }^{54}$.

148 Total GSL concentrations are high relative to other root Brassicaceae with the 149 primary compound being glucotropaeolin, and secondary glucolimnathin. This profile makes 
150 the crop somewhat unique among Brassicaceae, with only glucoalyssin and glucosinalbin

151 shared with more common cultivated species ${ }^{54}$

\section{Moringa (Moringa oleifera)}

Moringa species are non-cruciferous known for the high concentrations of aromatic

154 GSLs found within tissues ${ }^{55}$, and the unusual multiglycosylated conformation of their structures. Within leaf tissues 4- $\alpha$-rhamnopyranosyloxy-benzyl GSL (glucomoringin) is the

156 dominant compound, with lower concentrations of acetyl-4- $\alpha$-rhamnopyranosyloxy-benzyl,

157 which exists in three isomeric forms (Ac-Isomer-GSLs I, II, III); these latter molecules each 158 have an acetyl group at different positions on the rhamnose moiety. Due to the nature of these structures, standard methods of desulfation extraction are not recommended for moringa as

160 artifacts are formed, which are not reflective of intact GSL analysis. A method for the stable

161 extraction of these compounds has been developed by Förster et al. ${ }^{56}$. For this reason, papers

162 utilising desulfation extraction in moringa should not be taken as representative of GSL 163 profiles in planta.

164 The concentrations of GSLs reported for moringa leaves vary greatly (Table 1) ${ }^{57-60}$,

165 due to diverse growing environments and cultivar choice. Stems and roots tend to have lower 166 concentrations of glucomoringin and the acetyl isomers, but are noticeably higher than for 167 more commonly consumed crops such as kohlrabi and rutabaga.

\section{Mustard Greens (Brassica juncea)}

169 Like collards, mustard greens are high in GSLs $\left(\sim 25.9 \mathrm{mg} \cdot \mathrm{g}^{-1} \mathrm{dw}\right)$, but not widely 170 consumed due to their pungent and bitter tastes. Virtually all of the GSL profile is composed

171 of sinigrin ${ }^{18,19,36}$. There are a large diversity of accessions and cultivars of this species, which 172 provides an excellent resource for any breeding programs focused on culinary improvement.

\section{Radish (Raphanus sativus)}


Radish encompasses several varieties such as 'common' radish, China Rose ${ }^{11}$ radish, and Spanish black radish ${ }^{61}$. GSL concentrations reported from radish sprouts are very high ${ }^{11}$

176 compared to some reports for roots ${ }^{31,32}$. There is special interest in the compound 177 glucoraphasatin (also known as dehydroerucin) contained within radish tissues. It has been 178 postulated that the cell detoxification properties of its ITC (4-methylthio-3-butenyl ITC; 179 MIBITC) are comparable to sulforaphane (SFN) ${ }^{61}$.

\section{Rocket (Eruca sativa, Diplotaxis tenuifolia, Diplotaxis muralis \& Erucastrum spp.)} profiles. Other species, known as dogmustards (Erucastrum spp.), are also morphologically and phytochemically very similar to rocket.

Rocket species have five major GSL constituents: glucoraphanin, diglucothiobeinin, broccoli, total average GSL concentrations are higher for rocket (E. sativa: $\sim 15.3 \mathrm{mg} \cdot \mathrm{g}^{-1} \mathrm{dw}$; D. tenuifolia: $\left.\sim 11.2 \mathrm{mg} \cdot \mathrm{g}^{-1} \mathrm{dw}\right)$, but average glucoraphanin concentrations are lower $(E$. sativa: $2.0 \mathrm{mg} . \mathrm{g}^{-1} \mathrm{dw}$, D. tenuifolia: $\left.\sim 1.7 \mathrm{mg} \cdot \mathrm{g}^{-1} \mathrm{dw}\right)$.

Dogmustard and annual wall-rocket (D. muralis) profiles are somewhat different from 'wild' (D. tenuifolia) and 'salad' (E. sativa) species, but not as well studied. Dogmustard

192 GSL profiles are low in total concentration, but much of this is glucoraphanin. Annual wall193 rocket is high in this GSL too, by comparison to the commercially cultivated species, but few 194 cultivars have been characterised to-date. It is also high in diglucothiobeinin, DMB and 195 glucoerucin, giving a moderate total GSL concentration ${ }^{65}$.

197 papers accepting the hypothesis that they are products of extraction, without any supporting 198 experimental evidence. Work by Cataldi et al. ${ }^{66}$ a decade ago cast significant doubt on this 
assumption, but has largely gone unnoticed within the literature. The addition of tris(2carboxyethyl)phosphine (TCEP) to rocket extracts is common within the literature, and acts

201 as a reducing agent to break disulfide bonds, such as those that exist in DMB and 202 diglucothiobeinin. This so-called 'prevention of artifact formation' may actually be 203 drastically modifying the GSL profile from its natural configuration. As is seen in Moringa 204 spp., multiglycosylated GSLs do occur in nature, and so it is not inconceivable that these 205 compounds are naturally synthesised. Little is known about rocket GSL biosynthesis beyond compounds common to other species (e.g. glucoraphanin and glucoerucin). The pathway for glucosativin, and indeed dimeric GSL, biosynthesis has yet to be elucidated ${ }^{67}$, and even less 208 is known about their possible evolutionary and biological functions. In light of these unresolved questions dimeric compounds have been included in Table 1.

\section{Rutabaga (Brassica oleracea var. rapifera)}

Rutabaga (or swede) is consumed as a root crop and undergoes heavy processing and

212 cooking before consumption (i.e. peeling, chopping \& boiling) to soften the tissue. Raw GSL 213 concentrations have been reported to range between 3.5 and $5.6 \mathrm{mg} \cdot \mathrm{g}^{-1} \mathrm{dw}$, with progoitrin 214 reported as the most abundant GSL overall. The GSL profile is very diverse (Table 1), with 215 concentrations being particularly high in sprouts ${ }^{31,32,68}$.

\section{Spider plant (Cleome gynandra)} C. gynandra is known by several other common names, including: Shona cabbage,

218 African cabbage, spiderwisp, chinsaga and stinkweed. It is a popular leafy vegetable in 219 African traditional diets, and is routinely consumed for its purported medicinal properties. 220 Despite this popularity, current cultivars perform poorly, making the species an ideal 221 candidate for improvement ${ }^{69}$. Only one GSL is reported for spider plant, which is 3222 hydroxypropyl (glucoerysimumhieracifolium; Table 1) ${ }^{70}$, and is most concentrated in the 223 stems, siliques and flowers, with low leaf abundance ${ }^{69}$. 
Watercress is a crop that is gaining popularity in foods such as soups and smoothies,

226 as well as a traditional garnish ${ }^{71}$. Like rocket, watercress cannot be considered domesticated

227 due to a lack of breeding programs, and the tendency for commercial crops to be propagated

228 through clonal cuttings rather than seeds ${ }^{6}$. Its GSL composition is made up almost entirely of 229 gluconasturtiin. Its ITC is phenylethyl-ITC (PEITC) and is known to infer potential health 230 benefits in humans ${ }^{6}$.

231 Small amounts of indolic GSLs are also found within tissues (Table 1) ${ }^{36,71}$, but few 232 aliphatic GSLs have been reported. Total concentrations are modest $\left(\sim 5.0 \mathrm{mg} \cdot \mathrm{g}^{-1} \mathrm{dw}\right)$ but like 233 rocket species, cooking is not essential before consumption.

\section{White Mustard (Sinapis alba)}

235 White mustard leaves are not widely consumed due to their pungent attributes. They 236 are high in GSLs, which is almost entirely made up of the aromatic GSL glucosinalbin ${ }^{24}$. 237 These crops are predominantly used as biofumigants to control soil borne pests, such as 238 nematodes.

\section{PLANT BREEDING}

\section{General}

To quote Dr. Howard-Yana Shapiro, "It is not so much a question of more food. It is 243 more a question of better food" 72 . This statement encapsulates the ethos of breeding 244 Brassicaceae crops for enhanced GSL content. The trend in many crop breeding programs 245 over the last 60 years has been to increase yield, but this has come at the expense of 246 nutritional value in some instances ${ }^{73}$. It is hoped that by creating new and nutritionally dense 247 varieties, development of chronic diseases such as heart disease, cancer, and dementia can be 248 reduced through elevated concentrations in people's diets. 
250 breeding improvement over the last 150 years. It has been estimated that plant breeding has 251 accounted for $58 \%$ of the increases in maize yields seen between 1930 and $1980^{74}$, and if the 252 same concerted effort were to be made in Brassicaceae vegetables, it is not inconceivable that 253 compounds related to health-benefits could also be improved.

As pointed out by Goldman ${ }^{75}$, the irony is that many of the most beneficial health compounds are being bred out of crops because they are also responsible for pungency and sensory traits which consumers dislike. But this could be remedied through breeding by also looking at corresponding ratios with free sugars, some amino acids, and the relative 258 abundances of green-leaf volatiles. These have been shown to infer reductions in the 259 perceptions of such traits, while maintaining GSL concentrations ${ }^{76}$. The majority of genomic research for traits related to GSL metabolism has been 261 conducted in species such as A thaliana $^{77}$ and B. oleracea ${ }^{78}$. De novo genome sequencing 262 costs are still high, but falling, and this may entice new exploration of minor Brassicaceae 263 crop genomes in unprecedented fashion. There is however still a lack of understanding within 264 the literature of how new Brassicaceae varieties are developed commercially through plant 265 breeding methods. Such considerations are often absent from many nutritional, biochemical 266 and medical studies ${ }^{79}$. Individuals who are skilled and adept at computational genomics, 267 practical plant breeding, cultivation, analytical chemistry, and molecular biology techniques 268 are scarce, and having a deep knowledge of these fields and how they each interact is 269 challenging. This may be a reason why breeding efforts for phytochemical health traits to270 date have lagged behind physiological traits as it requires interdisciplinarity, even when 271 genomic information is available ${ }^{80}$. It is likely that in the private sector molecular breeding is 272 already well established in some Brassicaceae crops, but the degree to which these efforts 
273 have focused on GSL improvement are not readily apparent in commercial varieties available 274 for human consumption. A minority of people in Western countries consume an adequate amount of vegetables

$276^{81}$, and even fewer are likely to consume the recently reported optimum of ten-per-day ${ }^{82}$.

277 Breeders are recognising that getting consumers to eat more vegetables is not a realistic goal

278 . Instead, breeding strategies are concentrating on elevating compounds such as GSLs and 279 ITCs through selection so that the vegetables on offer to the consumer have a higher nutritional density. A large proportion of people could benefit from resultant new varieties 281 without having to modify their diets at all.

Much of the reported health effects are attributed to the GSL hydrolysis products of 283 glucoraphanin, glucoerucin and glucobrassicin ${ }^{84}$, which could be increased through appropriate breeding selection. The ITC and indole products (SFN, erucin and indole-3carbinol; I3C, respectively) have shown strong anti-carcinogenic effects in cell and animal studies ${ }^{85}$, but as will be discussed, these studies are limited in their applicability to humans and day-to-day consumption. There are many different factors that must be considered when breeding for modified GSL profiles. These will be discussed in the following sections; see Figure 1 for a summary.

\section{Breeding For Increased Glucosinolate Content}

As highlighted within Table 1 there is huge scope for individual crop improvement, as 292 evidenced by the diversity of GSLs and concentrations reported ${ }^{86}$. There are very few 293 examples of successful stabilisation of GSL concentrations across environments however ${ }^{87}$. 294 In order to develop enhanced varieties, species diversity must be scrutinised on a large number of cultivars/accessions before any breeding or genomics can take place ${ }^{79}$. 
298 numerous genotypes ${ }^{88}$. In order to develop such comparable resources for specific

299 Brassicaceae crops, breeders and researchers must have a comprehensive and extensive

300 knowledge of the cultivar breeding history, as well as a detailed knowledge of the GSL/ITC

301 types produced across environments ${ }^{89}$. Due to the complexity of the Brassica genome and

302 comparatively long life cycles of commercial crops, generating such genetic resources can

303 take decades.

The GSL pathway itself in Brassica and Arabidopsis is now well elucidated ${ }^{90}$ and it

is possible to identify orthologous genes for biosynthesis, transcriptional regulation and environmental response in other species ${ }^{87}$. MYB transcription factors control the complete GSL biosynthetic pathway, and also influence primary and sulfate metabolic pathways.

308 Differing transcript levels associated with MYB genes has been shown to affect indole GSL accumulation and the related metabolism products when plants are under pathogen stress ${ }^{91}$.

311 from tryptophan ${ }^{92}$. The gene BoGSL-PRO in B. oleracea converts methionine into 312 dihomomethionine and a chain-elongation process begins. This is further regulated by other 313 genes such as BoGSL-ELONG, and determines the carbon side-chain length (e.g. propyl, 314 butyl, pentyl, etc.). Other genes, such as BoGSL-ALK, further modify the R-group later in the synthesis pathway, and determine its final configuration ${ }^{77}$.

317 salicylic acid (SA), ethylene and jasmonic acid (JA). The synergistic or antagonistic crosstalk 318 between these three compounds determines the relative gene expression. Genes such as 319 CYP79B2, CYP79B3, CYP79F1 and CYP79F2 regulate the GSL biosynthesis pathway and 320 determine the overall GSL tissue profile, influencing the ratios between aliphatic and indolic 321 GSLs ${ }^{93}$. The level to which these and other biosynthetic genes are expressed depends on the 322 stimuli that initiate transcription, which can be both biotic and abiotic in nature. The 
323 relationship with primary sulfur metabolism is also important for GSL production, as two to 324 three sulfur atoms are required per aliphatic GSL molecule ${ }^{94}$.

325 The difficulty comes in generating breeding populations and having resources large 326 enough to develop such detailed knowledge in non-model species. Some papers have 327 advocated plant selection based on highest total GSL concentrations ${ }^{37,44}$, however this is an 328 unsophisticated approach, as not all GSLs produce breakdown products which are beneficial 329 for health, or positive for consumer acceptability. It also does not account for the potentially 330 harmful effects of specific GSLs when ingested in large quantities.

The most comprehensive and thoroughly tested example of a crop bred for enhanced

332 GSL content is Beneforté broccoli. This variety is an $\mathrm{F}_{1}$ hybrid derived from an original cross

333 between B. oleracea var. italica and Brassica villosa - a wild relative. The resultant variety is 334 able to assimilate sulfur at an enhanced rate, but also allocate greater amounts to methionine335 derived GSL production, rather than partitioned into the form of S-methylcysteine sulfoxide 336 (SMCSO). SMCSO levels are reduced by an average of $\sim 7 \%$ in plants containing the 337 introgressed B. villosa Myb28 allele, which in turn corresponds to a reciprocal increase in 338 glucoraphanin ${ }^{23}$. Sarikamis et al. ${ }^{20}$ also introgressed markers from B. villosa into broccoli which are associated with genes controlling the ratios between glucoraphanin and 340 glucoiberin. Selection for such genes could influence the downstream health beneficial 341 effects to the consumer.

342 Another area that could be targeted through breeding is hydrolysis product pathway 343 modification. It is known for example that a gene in A. thaliana called epithiospecifier 344 modifier 1 (ESMI) encodes a protein that inhibits epithiospecifier protein (ESP) function, 345 preventing it from converting GSLs into nitriles. Identifying, selecting and breeding for such 346 genes in Brassicaceae crops would be instrumental for improving the predictability of 347 hydrolysis product formation. Nitriles are much less bioactive than ITCs, and it would be 
348 favourable to decrease production of them ${ }^{95}$. This would lead to increases in ITC abundance 349 and enhance potential health benefits. Selecting for GSL accumulations alone is therefore not 350 sufficient to produce enhanced varieties; ITC abundance ratios must also be considered, as 351 these vary between species, varieties and genotypes ${ }^{96}$.

352 The variability of GSL concentrations in crops is due to genetic responses which are 353 influenced by environmental interactions ${ }^{17}$. The specific mechanisms responsible for such 354 large variations seen in varieties are complex ${ }^{97}$, and are not well understood in the commercial supply chain context. Few research papers have replicated the food system to determine the effects on GSL and hydrolysis product concentrations from a plant breeding 357 perspective ${ }^{98}$, and so it is difficult to make informed selections.

If products like Beneforté are to be developed for other species, it will require screening a large number of germplasm accessions in multiple environments, and phytochemical analysis throughout the commercial food chain ${ }^{86}$. Gene bank accessions are

361 an underutilised resource for breeding enhanced GSL accumulation traits. Screening these 362 large collections for enhanced traits is challenging, but wild genotypes with enhanced 363 glucoraphanin, glucoerucin, glucoraphenin, glucoraphasatin, glucoiberin, sinigrin and indole 364 GSLs may be found ${ }^{37}$. Blueprint breeding schemes for this method of introgression already 365 exist ${ }^{20}$ and so it is feasible that other crops could be developed with enough time and 366 resources.

367 Developing the genomic tools to improve varieties will also be necessary in future.

368 Despite detailed knowledge of the Arabidopsis and Brassica genomes there are few other 369 related crops that have been sequenced. Developing analogous genetic markers, linkage and 370 QTL maps using these species will serve for a time to screen for common GSL traits; 371 however, species such as rocket, radish and watercress have very different GSL profiles to $B$. 372 oleracea and Arabidopsis. As such, the time will come when full genome sequences will be 
373 required for these crops, to develop and enhance GSLs/ITCs with a high level of precision ${ }^{80}$.

374 Having species specific SNPs associated with GSL/ITC QTLs, genes, transcription factors,

375 and other plant defense and senescence pathways will be a powerful tool for enhancing crops,

376 and significantly reduce the generation number required to develop new breeding lines and

377 varieties ${ }^{89}$.

378 Breeding For Decreased Glucosinolate Content

379 From the late 1960s to the mid-1990s, much of the focus on GSLs and the associated

380 hydrolysis products was in relation to adverse health effects. There was concern surrounding

381 goitrogenic compounds, which are produced from the GSLs epiprogoitrin and progoitrin. The

382 oxazolidine-2-thiones and thiocyanate compounds produced by the hydrolysis of these GSLs

383 interfere with thyroid metabolism and induce a condition known as goiter. In the presence of

384 nitrate they also undergo nitrosation reactions, which is thought to have negative health

385 consequences ${ }^{99}$. High doses of GSL-derived nitriles have also been shown to be toxic ${ }^{100}$ but

386 reports are conflicting ${ }^{101}$. This has led to arguments for decreasing certain GSL compounds

387 in Brassicaceae crops through selective breeding. Progoitrin, sinigrin, gluconapin and indole

388 GSLs have all been cited as contributors to bitterness ${ }^{87}$, and a reduction is thought to 389 improve consumer acceptance ${ }^{102}$.

390 Sinigrin is common (in low concentrations) in important crops, such as cabbage, kale,

391 broccoli and Brussels sprouts (Table 1). The relative abundances in these are minor compared

392 to those found in mustard greens $\left(\sim 16.6 \mathrm{mg} \cdot \mathrm{g}^{-1} \mathrm{dw}\right)$, Chinese kale sprouts $\left(\sim 8.4 \mathrm{mg} \cdot \mathrm{g}^{-1} \mathrm{dw}\right)$

393 and collards $\left(6.5 \mathrm{mg} \cdot \mathrm{g}^{-1} \mathrm{dw}\right)^{18,19}$. The reduced bitter compound concentrations in commercial 394 crops have led some to speculate if this is partly the reason why pesticides have to be used so 395 intensely, as these varieties may be more prone to disease and herbivory ${ }^{102}$.

396 There are opposing opinions relating to sinigrin concentrations within Brassicaceae

397 foods. Sensory analysts advocate its reduction, as it is "regarded not as a health benefit but 
398 as a major sensory defect" ${ }^{102}$. Other studies by contrast have argued that sinigrin should be 399 increased due to the associated health benefits of allyl-ITC (AITC) ${ }^{37}$. Opinions expressed in 400 sensory quality reviews perhaps do not appreciate how difficult 'removal' is from a breeding 401 perspective, or what the effects are from a pest and disease management standpoint. These 402 compounds do not exist simply for the pleasure or displeasure of the human species. It 403 perhaps demonstrates a misunderstanding of the endogenous function of such compounds 404 within plants, and ignores any health benefits they have.

Progoitrin has been found to be prevalent in Chinese kale sprouts $\left(\sim 14.8 \mathrm{mg} . \mathrm{g}^{-1} \mathrm{dw}\right)$, collards $\left(2.9 \mathrm{mg} \mathrm{g}^{-1} \mathrm{dw}{ }^{18,19}\right)$, and leaf rape $\left(2.2 \mathrm{mg} \mathrm{g}^{-1} \mathrm{dw}{ }^{53}\right.$; Table 1). Arguments have been 407 made for progoitrin reduction in commercial crops because of the association between its 408 degradation products and goiter ${ }^{87}$. Double recessive alleles of GSL biosynthesis genes have 409 been identified and utilized in reducing concentrations in rapeseed to improve livestock feed

$410{ }^{90}$. Similar efforts to reduce harmful GSLs in other Brassicaceae is a realistic goal, but must 411 be targeted so that beneficial GSL accumulation is not affected.

412 Most arguments for the goitrogenic effects of GSLs are outdated and unsupported in 413 humans, however. Not all GSLs have goitrogenic breakdown products, and so are unlikely to 414 adversely affect otherwise healthy humans ${ }^{103}$. Most cited evidence stems from studies in 415 herbivores, such as rabbits and cows, which can ingest large amounts of seed meal and leaves 416 a day ${ }^{104,105}$. Assuming humans who eat Brassicaceae vegetables don't have a severe pre417 existing thyroid condition, and are not suffering iodine deficiency, there is little evidence of 418 healthy people developing goiter through ingestion of leaves, sprouts, roots, or indeed the 419 milk of animals that consume large GSL quantities ${ }^{103}$. At low-moderate levels the 420 compounds are beneficial to humans and enhance cellular defenses against cancer and other 421 diseases ${ }^{106}$. 


\section{CULTIVATION, POSTHAVEST PROCESSING \& STORAGE}

\section{General}

Improved genetics and phytochemical content through breeding must be synergistic

426 with improvements in Brassicaceae agronomy and cultivation methods. Important aspects to

427 be considered when attempting to enhance GSL concentrations through breeding include: 428 appropriate varietal selection, responses to fertilizer application, water availability, harvest 429 time/growth stage, light levels, and local temperature ${ }^{107-112}$. These factors and many more 430 can have a significant impact on the quantities of GSLs produced by plants (see Table 2). It 431 has been reported that GSLs can be enhanced through better and more informed cultivation 432 methods by up to ten times in the case of broccoli and cauliflower, and doubled in radish ${ }^{86}$.

\section{$433 \quad$ Varietal Selection}

It is well documented that GSLs and the respective breakdown products vary between species, within species, and even within individual cultivars ${ }^{86}$. The data collated in Table 1 gives examples of this variability, with large concentration ranges reported for species according to different growing environments (e.g. field or glasshouse).

It has been reported that a high degree of variation in GSL concentrations can exist between plants of the same variety (e.g. in Marathon broccoli heads) ${ }^{113}$. This poses a significant challenge, especially if varieties are uniform hybrids for morphological traits; and

441 indicates just how great an impact environment has upon GSL accumulation. In experimental 442 terms, it has been suggested that replicates be increased or samples pooled to create a 443 'representative' picture ${ }^{113}$. This is perhaps a neater approach statistically, but obscures the 444 inherent variation present between plants of the same variety, giving a false sense of 445 uniformity. If plants have not been selected for GSL profile modification, it is unsurprising 446 that such high variations exist ${ }^{96}$; therefore the development of uniform breeding lines and 447 varieties will mitigate this by considering individual plant chemotypes and sensotypes. 


\section{Light Intensity}

It has been demonstrated in A. thaliana that UV-B radiation can induce gene expression that promotes GSL accumulation ${ }^{114}$. In crops such as broccoli and cauliflower it

451 has also been observed that increased light levels can increase glucoraphanin and glucoiberin 452 concentrations within florets ${ }^{86,115}$. In an excellent recent paper by Moreira-Rodríguez et al.

$453{ }^{116}$ it was demonstrated that 24 hours after exposure to high UVB treatment, broccoli spouts 454 showed large increases in GSL concentrations. This included a $73 \%$ increase in 455 glucoraphanin, $78 \%$ increase in glucobrassicin, and a $\quad 170 \% \quad$ increase $\quad$ in $\quad$ 4456 methoxyglucobrassicin. The authors indicated that UVB radiation triggers signal transduction 457 pathways, leading to up-regulation of GSL biosynthesis genes as part of a UV protection 458 mechanism. Within a segregating population of plants, it is theoretically possible to select for 459 plant with genes predisposing them for such higher accumulations. With more advanced 460 genetic analysis of such genes, it should also be possible to identify polymorphisms 461 underlying the propensity for increased glucoraphanin and indole GSL biosynthesis. As the 462 authors discuss, it may be theoretically possible to 'tailor' GSL profiles to a degree, by 463 exposing sprouts to differing combinations of UVA and UVB light intensities. As with most 464 studies of this kind, only a single variety of broccoli was used, and so it is not possible to determine how much these responses vary according to genotype. It was also not determined 466 how these respective increases affected ITC/nitrile/indole production. Other studies have 467 noted that GSL profiles are not necessarily indicative of myrosinase activity or hydrolysis 468 product profiles ${ }^{110}$. Nevertheless, the results indicate that this is an area for future study, and 469 it would be intriguing to determine how such responses vary within segregating populations 470 of broccoli and other Brassicaceae.

471 GSL accumulation is generally much higher when plants are exposed to longer 472 periods of light. A study by Kim et al. ${ }^{117}$ showed that GSL concentrations of Chinese 
473 cabbage seedlings were up to 6.9 times higher in plants exposed to light ten days after 474 sowing. This suggests that raising seedlings in the dark for several days may increase the 475 potential accumulations within the plants at later developmental stages.

GSL concentrations also fluctuate according to diurnal rhythms imposed by exposure

477 to light and dark. Huseby et al. ${ }^{118}$ demonstrated that relative expression of genes associated 478 with GSL biosynthesis in A. thaliana were significantly increased in plants grown in dark 479 conditions before being exposed to light, compared with those which were only exposed to a 480 normal diurnal cycle. This implies not only that GSL biosynthesis can be influenced by light, 481 but also that GSL concentrations can be enhanced through controlled exposure. Huseby et al. 482 also saw GSL concentrations peak eight hours after light exposure was initiated in a diurnal 483 cycle, with concentrations then subsequently declining. This has large implications for 484 commercial operations that may harvest at specific times during the day. More research is needed to understand how these mechanisms function in commercial crops, but it is likely that recommendations for optimum harvest times could be generated in order to maximise 487 GSLs.

Different light wavelengths that are applied to Brassicaceae crops also cause differing effects on GSL concentrations. Blue light has been shown to increase total GSLs in ezo490 wasabi leaves ${ }^{50}$ and turnip roots ${ }^{119}$ (Table 2) via possible activation of GSL biosynthesis 491 enzymes. This mechanism has been postulated but not verified, and is thought to impact 492 aliphatic and aromatic GSLs, not indolic, as there is no corresponding increase for these 493 compounds under blue light ${ }^{120}$. This phenomenon could be exploited in controlled 494 environment cultivation or vertical farming methods, to improve the nutritive value of niche 495 microleaf and baby leaf crops. In contrast, increased levels of red and far-red light have 496 resulted in elevations of gluconasturtiin in watercress. It has also been reported that red light 
497 (640 nm) applied to kale sprouts increases the production of specific GSLs, such as sinigrin;

498 but other wavelengths have no significant effect ${ }^{107}$.

\section{Environmental Temperature}

Unlike light intensity, increasing temperature does not have a reciprocal effect on

501 GSL concentrations. Myrosinase activity is known to increase with higher daily mean

502 temperature, and it is hypothesised that this leads to increased GSL degradation upon harvest

$503 \quad{ }^{86}$. It has been noted that high summer field temperatures have a detrimental effect on specific

504 GSL concentrations at the point of commercial harvest in 'salad' rocket, but this is not

505 indicative of postharvest concentrations, which have been observed to increase during shelf

506 life storage ${ }^{98}$.

507 There are reports of increasing GSL concentrations with warmer weather in kale and 508 red cabbage ${ }^{1}$, but these come from spring and autumn comparisons where differences in light

509 levels may contribute more to the elevations observed than the relative increase/decrease in

510 temperature. Steindal et al. ${ }^{52}$ found a specific increase of sinigrin in kale at low growing 511 temperatures. Schonhof et al. ${ }^{121}$ analysed broccoli at different growth temperatures and 512 found that low temperatures increased aliphatic GSLs, and high temperatures increased 513 indolic GSLs. This trend was not observed by Steindal et al. ${ }^{52}$ in kale, where both high and

514 low temperatures $\left(32^{\circ} \mathrm{C} \& 12^{\circ} \mathrm{C}\right)$ increased aliphatic GSLs. The authors suggested that cold 515 temperature stress is beneficial for GSL accumulation, but is dependent on the organs and 516 species in question.

\section{Water Availability}

518 In broccoli plants it has been observed that a reduction in water availability causes 519 large increases in GSL concentrations ${ }^{86}$. This may be due to a concentration effect within the 520 plant tissues, but it is also possible that this is a defensive response in times of vulnerability 521 and stress. Various reasons have been hypothesised for such increases when plants are 
522 experiencing drought, including increased synthesis of sugars, amino acids, and sulfur 523 availability ${ }^{107}$.

524 As with other abiotic factors influencing GSL concentrations, there are conflicting 525 reports. Some studies suggest that increased rainfall in the spring (coupled with increasing 526 temperatures) increases GSLs ${ }^{1}$; but these interacting factors, combined with lengthening 527 days and stronger light might be the primary cause. The timing of irrigation before harvest 528 also impacts the abundance of GSLs, and is another factor for consideration ${ }^{107}$.

\section{Sulfur Application}

530 Fertilizer application to Brassicaceae crops is common practice in the commercial 531 setting but can lead to changes in GSL composition. High sulfur doses applied to crops can 532 facilitate sizeable increases in GSLs with known health benefits (Table 2) such as 533 glucoraphanin ${ }^{23}$. Application to broccoli plants (600 $\mathrm{mg} \mathrm{S} \mathrm{plant}^{-186}$ ) has been shown to 534 increase concentrations. Combined with a reduction in watering, this can also boost the 535 concentration, but at the sacrifice of yield ${ }^{86}$. Fertilizer cost may be a limiting factor for many 536 growers, however. So while sulfur application to enhance GSLs may be effective, farmers 537 will not be likely to adopt it unless yields can be maintained.

538 In radish, a lower amount of sulfur has been reported to be efficacious in increasing 539 glucoraphasatin concentrations $\left(150 \mathrm{mg} \mathrm{S} \text { plant }^{-1}\right)^{86}$, meaning that application on specific 540 crops could be more preferable and affordable from a commercial perspective. Increases in 541 total GSLs, sinigrin, glucobrassicanapin, gluconapin and progoitrin have also been reported 542 with increased sulfur ${ }^{107}$. For an excellent review of sulfur assimilation, its relationship with 543 GSL biosynthesis, and the underlying genetic mechanisms responsible in Brassica species, 544 see Borpatragohain et al. ${ }^{122}$.

\section{Nitrogen Application}


With decreasing nitrogen application GSLs have been observed to increase ${ }^{86}$. In

547 combination with sulfur fertilization $\left(60 \mathrm{~kg} \cdot \mathrm{ha}^{-1}\right)$, increasing nitrogen $\left(80-320 \mathrm{~kg} \cdot \mathrm{ha}^{-1}\right)$ has

548 been shown to be ineffective at increasing total GSL concentrations in turnip, but can shift

549 the ratio towards greater indolic GSL production. This is in contrast with sulfur applications

550 at a low level $\left(10-20 \mathrm{~kg} \cdot \mathrm{ha}^{-1}\right)$ and increasing nitrogen, where aromatic and aliphatic GSLs

551 decrease ${ }^{123}$.

552 Experiments by Schonhof et al. ${ }^{124}$ in broccoli found that inadequate nitrogen

553 increased GSLs, and inadequate sulfur decreased them. Hirai et al. ${ }^{125}$ found that under

554 nitrogen and/or sulfur limited growth conditions in A. thaliana, the genes encoding

555 myrosinase enzymes were down-regulated in order to facilitate GSL storage in leaf tissues.

556 The strategy for fertilizing commercial Brassicaceae crops should therefore take these factors

557 into account if enhanced health properties are to be produced.

\section{Methionine Application}

Another means of increasing GSL concentration in crops is amino acid application

560 (Table 2). As aliphatic GSLs (such as glucoraphanin) are derived from methionine, 561 application to crops could enhance production in species such as broccoli ${ }^{86}$. It has been 562 applied to broccoli sprouts and rutabaga with encouraging results. In these crops, total GSLs 563 were increased by $19 \%$ and $85 \%$, respectively ${ }^{11}$. The effects on glucoraphanin and 564 glucoiberin in the broccoli sprouts were modest, with a $7 \%$ increase. By contrast, indolic 565 GSLs 4-hydroxyglucobrassicin, glucobrassicin and 4-methoxyglucobrassicin increased by $56628 \%$. In the rutabaga the large total increase was due to elevations in both aliphatic and 567 indolic GSLs.

568 Baenas et al. ${ }^{11}$ have suggested that the effects are strongest at lower concentrations (5 $569-10 \mathrm{mM}$ applications) which result in total GSL increases of $21-23 \%$ in sprouts. Other 570 studies have applied up to $200 \mathrm{mM}$ of methionine and still seen increases of up to $28 \%{ }^{126}$, 
571 though the application method was different. The effects on specific GSLs in sprouts related

572 to health benefits such as glucoraphanin, glucoraphenin and glucoraphasatin seem not to be

573 affected by methionine application according to Baenas et al. ${ }^{11}$, but this may be related to the

574 immature growth stage at which plants were tested.

\section{Selenium Application}

576 Selenium is an essential micronutrient for humans. There is a significant relationship

577 between the amount of selenium within the diet and the risk of developing conditions such as

578 cancer, heart-disease and immune system diseases ${ }^{127}$. It has been estimated that $33 \%$ of

579 children (age $11-18$ ), $39 \%$ of adults (age 19-64), and $44 \%$ of older adults (age $65+$ ) consume

580 less selenium than the recommended Lower Reference Nutrient Intake (LRNI)

581 recommendation ${ }^{128}$.

582 Research has been conducted to apply selenium to crops (such as broccoli) to enhance

583 nutritional properties ${ }^{129}$. Studies have shown that excess selenium application can reduce

584 GSL content by $90 \%{ }^{30}$. By contrast, selenium application to radish plants has been shown to

585 increase glucoraphanin concentrations within roots ${ }^{129}$. With more moderate application, SFN

586 concentrations can be increased in broccoli ${ }^{130}$, but other studies have reported no change in

587 sprouts, indicating the optimum benefits of application depend on growth stage ${ }^{127}$.

588 Plant-Bacterial Interaction

589 In a 2009 paper, Schreiner et al. ${ }^{36}$ demonstrated that an auxin-producing bacterial

590 strain (Enterobacter radicicitans DSM 16656) could influence and utilise GSL

591 concentrations in several Brassicaceae species. The bacterial strain colonized the plant 592 phyllosphere, and it was hypothesised that the response could be two-fold: 1) that GSL 593 concentrations increased due to defense mechanism activation, and 2) that the bacterial auxin 594 supply to leaves could induce GSL synthesis by metabolism of indole-3-acetaldoxime. The 595 species with the greatest bacterial growth of E. radicicitans in vitro had high aliphatic GSL 
concentrations (B. rapa \& B. rapa var. chinensis), whereas aromatic GSL-containing species

597 showed little increase (N. officinale).

598 Very few papers have linked bacterial colonisation of leaves with GSL accumulation,

599 but Bell et al. $2017^{98}$ found strong correlations between GSL concentration and bacterial

600 load of rocket within the commercial supply chain after processing. This could be suggestive

601 of defensive responses due to damage incurred through processing, but also that bacteria

602 influence the GSL profile in some way during shelf life. This is an area of research that

603 requires much more thorough exploration.

604 Developmental Stage (Ontogeny)

605

The developmental stage (ontogeny) at which plants are harvested is a significant

606 determining factor in the GSL concentrations that will be ingested by consumers ${ }^{37}$. Crop

607

maturity from a culinary perspective does not always coincide with peak GSL accumulation,

608

as this can vary over life cycle. In broccoli heads, the highest glucoraphanin concentrations

609 have been observed at 180 days after sowing, with a subsequent decline at the onset of

610 flowering ${ }^{14}$. In contrast, Chinese kale GSL concentrations are reported to peak at the sprout 611 growth stage ${ }^{47}$.

Sprouts are often the subjects of environmental, elicitation and postharvest studies to increase GSL accumulation ${ }^{47}$. This is because of the fast turnaround times in which crops of

614 such age can be sown and harvested, and because it has been reported that GSLs are of higher 615 concentration at this point. This is thought to be due to a concentration effect as leaves are 616 not fully expanded, and therefore not diluted by growth and expansion ${ }^{11}$. Broccoli, 617 cauliflower and cabbage studies have shown that total aliphatic GSL concentrations decline 618 during a seven day sprouting period, but that indolic GSLs increased ${ }^{107}$. This is a very short 619 space of time compared to the entire plant life cycle, and not representative of peak 620 accumulation. Baenas et al. ${ }^{11}$ specified that eight-day-old sprouts were optimum for 
621 enhancing GSL concentrations, broccoli, turnip, rutabaga, and radish all much higher than

622 their average reported mature values. They reported broccoli glucoraphanin concentrations of

$62318.3 \mathrm{mg} \cdot \mathrm{g}^{-1} \mathrm{dw}$. China Rose radish sprouts are especially rich in glucoraphenin and

624 glucoraphasatin, and rutabaga high in progoitrin. Qian et al. ${ }^{46}$ reported total concentrations

625 as high as $98.2 \mathrm{mg} \cdot \mathrm{g}^{-1} \mathrm{dw}$ in Chinese kale (grown hydroponically). It may be that sprout

626 concentrations vary between species and varieties, and this needs to be addressed by

627 analysing multiple commercial varieties and wild cultivars of each species. Sprout

628 consumption is an uncommon practice for the consumer at the present time, so research in the

629 mature crop may be of more relevance for enhancing GSL intake. That being said there is

630 little consensus on what the best harvest point is to maximise GSL concentrations for

631 individual crops, or even commercial varieties. As pointed out by Bell et al. ${ }^{62}$, some studies analysing the GSL composition of mature rocket leaves are often long after a commercially

633 relevant time point, and so this needs to be addressed with consideration for common 634 commercial practices.

An excellent paper published recently by Hanschen \& Schreiner ${ }^{110}$ explored the 636 effects of ontogeny upon GSL and ITC concentrations in broccoli, cauliflower, cabbage, savoy cabbage, and red cabbage sprouts and heads. Importantly, they also tested multiple varieties for each crop, highlighting how important this is as a consideration for enhancing 639 health-promoting compounds. It was observed that both the types and concentrations of GSLs 640 and hydrolysis products differed between sprouts and heads, with up to ten times more 641 present in the former than the latter. It was also apparent that for the tested varieties nitriles 642 were the predominant hydrolysis product, indicating that this is an area for potential 643 improvement through selection of genes related to ITC-nitrile ratios. The authors also pointed 644 out that 'mini heads' contained the greatest concentrations of ITCs (such as sulforaphane), 645 and are perhaps a better alternative to fully mature heads in terms of maximizing ITC 
646 consumption. The only drawback of the study was that the reported concentrations were for

647 raw plant material, not cooked. As discussed in the following 'Consumer' section, this may

648 have drastic effects upon myrosinases and ESP proteins, and determining the amounts and

649 types of hydrolysis products present at the point of ingestion.

650 In watercress, a crop which does not require cooking, an ontogenic study by

651 Palaniswamy et al. ${ }^{131}$ showed that leaves harvested at 40 days of growth after transplantation

652 contained $150 \%$ higher PEITC than leaves at 0 days. This was a linear increase with no

653 significant changes at 50 and 60 days. In species such as watercress where establishment of

654 new breeding programs and varieties is difficult (due to the commercial preference of

655 vegetative propagation), the selection of an optimum harvest date may be the most effective

656 way in the short-term to promote maximum ITC formation in commercial crops.

657 Postharvest Commercial Processing \& Storage

658 It is well known that GSL profiles change during postharvest processing and storage.

659 Processing can alter food matrix composition, which increases the accessibility and

660 bioavailability of compounds ${ }^{34}$ such as ITCs. The atmosphere in which produce is stored 661 also affects GSL concentrations ${ }^{13}$.

662 In rocket species simulated shelf life storage has revealed that individual GSLs such

663 as diglucothiobeinin increase ${ }^{63}$. After harvest and commercial processing significant

664 increases in glucosativin and SFN have been observed. This indicates that postharvest

665 industrial practices induce GSL synthesis and may boost the health beneficial effects for the

666 consumer ${ }^{98}$. Glucoraphanin has likewise been shown to increase ${ }^{63}$ or remain stable ${ }^{98}$

667 throughout cold storage conditions, and the increases in ITCs over nitriles during storage has

668 also been documented ${ }^{96}$. These results are encouraging, as it was previously assumed that

669 concentrations would be detrimentally affected by rigorous harvest and washing procedures. 
671 to increase by up to $42 \%$, but at high storage temperature $\left(10^{\circ} \mathrm{C}\right){ }^{132}$. It has been suggested

672 that increases in glucoraphanin are due to the vegetative state of the broccoli heads ${ }^{14}$. At

673 cold-chain temperatures $\left(0-4^{\circ} \mathrm{C}\right)$ results are more conflicting; Rybarczyk-Plonska et al. ${ }^{14}$

674 reported no changes in GSL concentrations, Fernández-León et al. ${ }^{133}$ reported increases in

675 aliphatic GSLs and decreases in indole, and Rodrigues \& Rosa ${ }^{134}$ saw stable indole GSLs, 676 but a $31 \%$ reduction in glucoraphanin.

677 When combined with the addition of low postharvest light $\left(13-25 \mu \mathrm{mol} \mathrm{m} \mathrm{m}^{-2}\right)$ at $67810^{\circ} \mathrm{C}$ and $4^{\circ} \mathrm{C}$, aliphatic GSL concentrations have been observed to increase by up to $130 \%$, 679 with 4-methoxyglucobrassicin also increasing ${ }^{14}$. It is unclear if the shift to warmer 680 temperature during storage has any implication for tissue degradation or increased microbial 681 load. These increases are arguably the result of stress responses due to the shifts in 682 temperature from $0^{\circ} \mathrm{C}^{14}$, with the relative increases seen are dependent upon dose, frequency, 683 and duration of UV-B exposure ${ }^{135}$. Increases have been reported for 4684 hydroxyglucobrassicin at $18^{\circ} \mathrm{C}$ with $25 \mu \mathrm{mol} \mathrm{m} \mathrm{m}^{-2} \mathrm{~s}^{-1}$ light ${ }^{14}$, but it is difficult to see how these 685 recommendations can be applied to commercial produce.

686

\section{THE CONSUMER}

688 General

689 Some consumers are becoming more health conscious, and while not always the 690 primary decision in purchasing and eating food, nutritional content is an aspect which is more 691 evident in the decision-making process ${ }^{86}$. They are looking for products that are "healthy" 692 and "natural", and scrutinizing the nutritional value of Brassicaceae crops ${ }^{136,137}$. This is 693 especially the case for young consumers, who are open to trying new foods ${ }^{138}$. That being 694 said, the average contribution to the "five-a-day" that Brassicaceae account for is between 0.2 
$695-0.5$ servings ${ }^{137}$, and even further from the optimum "ten-a-day" ${ }^{82}$. This section will

696 explore the processes relating directly to the consumer after purchase, such as cooking,

697 sensory perceptions and preferences, and human health and metabolic aspects.

698 Previous reviews have addressed the mechanisms involved in processing and the 699 changes initiated in GSL and ITC profiles ${ }^{2,139}$. Few however have done so with the purpose 700 of using such data to inform plant-breeding selections and improving the varieties 701 themselves, rather than the methods used to process them. The effects of cooking on ITC 702 formation in one variety of cabbage may not be the same as another, for example. The taste 703 of one rocket variety may be preferred over another because of underlying phytochemical 704 interactions with ITCs. The relative stability of myrosinases between broccoli varieties may 705 determine the formation of ITCs over nitriles. All of these are quantifiable traits that can be 706 used to inform breeding selections, and can be linked to the biochemistry and physiology of 707 plants, which are ultimately determined at the genetic level.

\section{Cooking Methods}

The means by which produce is prepared by the consumer influences the amounts of 710 beneficial compounds that are ingested ${ }^{140}$. This includes all aspects relating to peeling, 711 chopping and cooking. Depending on the species, this affects GSL concentrations and the 712 production of hydrolysis products that are responsible for health benefits.

The heat generated by cooking often leads to myrosinase inactivation at temperatures

$714>60^{\circ} \mathrm{C}^{18}$, and is a barrier to increasing health benefits. In addition to this, high temperatures $715\left(\geq 100^{\circ} \mathrm{C}\right)$ also cause GSL degradation when tissue water content is $>34 \%{ }^{33}$; this means 716 commercial produce would be severely affected. Boiling crops like watercress results in 717 severe GSL losses - probably through such thermal degradation ${ }^{71}$.

718 Steaming of vegetables has produced some conflicting results. Papers have reported 719 GSL losses, some no-significant change, and others have observed significant increases ${ }^{140}$. A 
720 study by Giallourou et al. ${ }^{71}$ on the effects of cooking on watercress, found that steaming

721 significantly increased gluconasturtiin concentrations (from 1.8 to $2.0 \mathrm{mg} \cdot \mathrm{g}^{-1} \mathrm{dw}$ ), and

722 Gliszczyńska-Świgło et al. ${ }^{141}$ reported a 1.2-fold increase in total GSLs in broccoli. In the

723 latter study, the authors hypothesised that this increase was time dependent, having seen no

724 significant effects before 3.5 minutes of steaming. Similarly with watercress, steaming for 2-

7255 minutes saw no major losses in GSLs. This suggests there is an optimum time to steam in

726 order to increase or preserve GSL bioavailability and avoid their breakdown due to prolonged

727 heat. Another study looking at broccoli steaming found an increase in total GSL content ${ }^{141}$,

728 however it is speculated that this is because cooking and heating increases compound

729 extractability ${ }^{33}$. This translates into greater bioavailability and benefits to the consumer ${ }^{30}$,

730 and it has been demonstrated in simulated in vitro digestion of cauliflower that sinigrin

731 bioavailability is increased by $29.5 \%$ and $114.7 \%$ after steaming and boiling, respectively ${ }^{142}$.

732 Ciska \& Kozłowska ${ }^{143}$ hypothesised that the disintegration of tissues by heat releases GSLs

733 which would otherwise be bound within cell walls; this would account for the relative

734 increases observed. But GSL bioavailability is of little significance for human health unless

735 there is a means by which they can be hydrolysed into ITCs/indoles.

Microwaving has been found to induce severe GSL losses in numerous studies. As

737 with steaming, it has been hypothesised that microwaves cause a cell structure collapse

738 leading to contact between GSLs and myrosinase ${ }^{140}$. No studies have determined if there is a

739 respective increase in ITCs as a result, or whether myrosinase is inactivated due to high

740 temperatures.

741 Matusheski et al. ${ }^{144}$ have demonstrated that cooking chopped broccoli heads at $60^{\circ} \mathrm{C}$

742 for $5-10$ minutes increases and favors SFN production. It was hypothesised that the $60^{\circ} \mathrm{C}$

743 heat inactivated ESPs leaving myrosinase active and free to convert GSLs to ITCs. Such

744 optimization methods for maximizing content signify that high SFN concentrations could be 
745 ingested even after cooking, providing that heating is not too prolonged or intense. Breeding

746 efforts should therefore focus on selecting plant lines with greater myrosinase function and

747 stability ant higher temperatures.

\section{Condiment Selection}

749 There is some evidence to suggest that the condiment with which Brassicaceae are 750 ingested aids in ITC production and enhances absorption within the gastrointestinal tract 751 (studied in rats). Ippoushi et al. ${ }^{145}$ have demonstrated that when raw, grated daikon radish is 752 prepared in oil, the ITC absorptive content was increased compared to water. This perhaps 753 suggests that oil stabilizes and preserves ITCs before ingestion.

754 The addition of exogenous myrosinase to cooked Brassicaceae has also been 755 suggested as a means to boost GSL conversion to ITCs ${ }^{18}$. This commonly means the addition 756 of mustard to foods, but many people find the pungency of this condiment too intense.

\section{Sensory Perceptions}

The effects of differing GSL content in produce on the consumer and their tastes are very complicated ${ }^{68}$. It is known that not all consumers are the same in their preferences for

760 Brassicaceae vegetables due to differences in genotype and life experience ${ }^{146}$. Certain GSLs and their hydrolysis products have been attributed with bitter tastes. The rejection of bitter tastes by some consumers is a barrier to encouraging greater consumption ${ }^{13}$, especially if

763 breeding goals are to increase quantities within tissues ${ }^{102}$. It has been demonstrated that

764 bitterness perceptions can be reduced or even masked ${ }^{147}$ by enhancing relative sugar 765 concentrations within tissues ${ }^{146}$. Therefore, through selective breeding, health-beneficial bitter compounds can be enhanced without negatively impacting on consumer acceptance.

768 efforts to breed for health benefits. These two should go hand-in-glove, but often are not 769 considered together in published research papers. The trends seen in consumers preferring to 
770 purchase more nutritious foods has not been mirrored by an improvement of the sensory

771 properties of the foods themselves ${ }^{148}$. This means that if this trend is to be expanded or

772 sustained, new varieties will need to be produced with enhanced sensory and nutritional

773 traits, not just one or the other.

774 Gut Microflora

775 Many cooking studies on Brassicaceae have reported significant increases in available

776 GSLs, but often omit that the temperatures involved would significantly or completely

777 inactivate myrosinases. This means that any GSL to ITC and indole conversion would be

778 reliant upon gut microflora. Some bacteria found within the human gut are known to possess

779 myrosinase-like enzymes. They act as a potential means by which humans can ingest ITCs,

780 even if cooking has inactivated plant myrosinase. It has been speculated that such bacteria 781 play a vital role in mediating the health benefits of ITCs, but the degree to which this occurs 782 is unclear and requires extensive study ${ }^{106}$.

\section{Consumer Health Benefits - Evidence From Cell \& Animal Studies}

The vast majority of knowledge accumulated around ITCs comes from cell and animal studies. ITCs and indoles are classed as anticarcinogens and act as blocking agents that increase cytochrome P450 activity ${ }^{149}$; see Figure 2 for chemical structures of the most widely studied compounds. The prevailing mechanism of action suggested within studies is phase II metabolic detoxification enzyme activation, such as glutathione-S-transferase (GST), NAD(P)H:quinone oxidoreductase (NQO), and phase I enzyme inhibition ${ }^{149-151}$. Waste

790 metabolites produced by cells are excreted into the blood and converted by the liver into 791 mercapturic acid; this is then excreted in the urine ${ }^{96}$.

SFN has been linked with detoxification pathway modification, which increases the

793 excretion of potential carcinogens from cells ${ }^{30}$. It is also linked with prostate cancer cell 794 apoptosis, and has been shown to act in a dose-dependent manner against kidney and 
795 colorectal cancer cell lines by inhibiting histone deacetylation ${ }^{150}$. There is also evidence to 796 suggest that the increase in phase II detoxification enzymes by SFN could help reduce 797 damaging effects in basal ganglia, and protect dopaminergic neurons ${ }^{10}$; this has significant 798 implications for neurodegenerative diseases. For an excellent review of the neuroprotective 799 effects of SFN see Giacoppo et al. ${ }^{10}$.

800 ITCs such as PEITC (abundant in watercress) and AITC (abundant in mustards) have 801 been shown in cell studies to inhibit tumorigenesis, protect DNA from damage, and induce 802 apoptosis. The specific structure and length of the alkyl chain an ITC has is linked to its 803 efficacy in inhibiting tumor formation. Phenylhexyl ITC $\left(\mathrm{C}_{6}\right.$; PHITC) is $50-100$ times more 804 efficacious in this respect than PEITC ${ }^{150}$ in studies focused on reducing the effects of 805 smoking. The dose used however was $5 \mu \mathrm{mol}(1.1 \mathrm{mg})$ per mouse for four days - far in 806 excess of what an equivalent human could realistically ingest ${ }^{152}$.

807 The juice extracts from Brassicaceae plants such as 'salad' rocket ${ }^{63}$, garden cress ${ }^{153}$ 808 and radish ${ }^{61}$, and their application to cancerous cell lines, such as colon cancer (HT-29) or 809 hepatoma (HepG2) cells, are used to establish antigenotoxic, detoxification or 810 antiproliferative effects. In rocket, it has been shown that extracts have protective effects 811 against DNA damage in comet assays ${ }^{63}$. ITCs and their cysteine conjugates have shown 812 efficacy in inhibiting HL-60 leukemia cells at concentrations as low as $0.8 \mu \mathrm{mol} . \mathrm{L}^{-1}{ }^{150}$. In the 813 use of other cell lines, the results are more mixed: some respond with an increase in CYP 814 activity when exposed, whereas others do not ${ }^{149}$.

815 Similar effects have been associated with indolic-GSL breakdown products, such as 816 I3C and 3,3'-diindolylmethane (DIM). Dietary studies conducted in rats have found that 817 phase II detoxification enzymes are enhanced in the stomach, liver and small intestine after 818 consumption of these compounds. Indoles are thought to act somewhat differently to ITCs 819 however, inhibiting cancer cells through cytostatic mechanisms, rather than apoptosis ${ }^{96}$. 
822 human health ${ }^{154}$, but the compounds responsible and the interactions with genotype are not

823 clear. It is assumed that what is beneficial for one person to consume, is beneficial for all

824 people. This is not the case for many food types, and some evidence suggests it is the same

825 for Brassicaceae vegetable consumption. It is known that human metabolic genotypes vary in 826 the degree of beneficial effects that they will impart after ingestion of phytochemical 827 compounds ${ }^{155}$, and adds an additional layer of complexity to producing Brassicaceae with 828 enhanced GSL/ITC traits ${ }^{75}$.

829 The quantities required to elicit benefits in humans (both acute and chronic) are 830 difficult to define due to variations in bioavailability within Brassicaceae food matrices and 831 GSL-metabolism by gut microbiota in subjects ${ }^{156}$. The experimental quantities used in 832 clinical research trials frequently do not translate into realistic or sustainable amounts that the 833 average person can achieve. A study by Bogaards, Verhagen, \& Willems ${ }^{157}$ demonstrated 834 that after human males consumed $300 \mathrm{~g}$ of Brussels sprouts per day, there was a significant 835 increase in GST products in the blood compared to those on a GSL-free diet. While 836 indicative of an underlying metabolic mechanism for ITC degradation, few people would be 837 willing or able to consume such large Brussels sprout quantities on a daily basis. The 838 impracticality of studies in the 'real world' and to ordinary people often detracts from the 839 importance of the mechanistic findings. Doses are also often administered in a form that 840 would not regularly be consumed (i.e. as a drink or powder supplement) ${ }^{158}$, which limits the 841 relevance of results and the conclusions drawn. This raises the question: are the beneficial 842 effects seen in trials 'real-world' effects, or just ones induced by extreme acute consumption? Epidemiological studies looking at cancer risk vs. Brassicaceae vegetable 844 consumption have reported mixed results. Studies in patients with prostate cancer, for 
845 example, have found both significant inverse associations and no significant associations. For

846 other cancers, such as endometrial, the risk reductions reported are moderate ${ }^{151}$. Data are

847 encouraging, but do not identify or distinguish the modes of action that are responsible ${ }^{106}$.

848 ITCs and indoles are strong candidates, but other compounds such as flavonoids, carotenoids

849 and anthocyanins are also present in Brassicaceae. It is unlikely that these compounds act in

850 isolation within the human body, and it may be the combined effect of ingesting a diverse 851 range of phytochemicals contributes towards such risk reductions ${ }^{63}$.

852 Genetic studies on humans have identified several genes that play a role in ITC 853 metabolism. GST loci and the associated GSTM1, GSTT1 and GSTP genotype 854 polymorphisms impact the relative protective effects of ITCs that an individual will receive.

855 Individuals that are GSTT1-null and GSTM1-null are at higher risk of developing some 856 cancers, such as renal cell carcinoma. Those who carry present copies of both GSTT1 and 857 GSTM1, and have only a low Brassicaceae intake, are still at a lower risk than null 858 individuals by comparison ${ }^{151}$. It has been estimated that up to $40 \%$ of the population may 859 benefit from increased Brassicaceae consumption due to the elevated risk associated with 860 some null genotypes ${ }^{13}$. Breeding goals selecting for certain GSLs/ITCs have not considered 861 consumer genotype as a variable, but in future this must be an expressed goal if populations 862 are to gain full benefits of newly developed varieties ${ }^{75}$. This means that selection and 863 enhancement for other compounds such as flavonoid glycosides, anthocyanins and 864 carotenoids may be practical way of ensuring an 'all-round' health benefit to Brassicaceae 865 crops.

866 It is well documented in clinical studies of raw vs. cooked vegetables that cancer risk 867 (of multiple types) decreases with raw plant matter ingestion ${ }^{159}$. Consuming uncooked 868 species (such as rocket or watercress) increases the contact between GSLs and myrosinase 869 and the amounts of ITCs absorbed ${ }^{18}$. Due to the detrimental effects of cooking on GSLs and 
myrosinase, $B$. oleracea crops may not be as effective/efficient as uncooked species at

871 eliciting such reductions in overall risk.

872 The reported anticancer effects of Brassicaceae in the diet are poorly substantiated by

873 empirical quantification of the total GSL/ITC amounts that are ingested and absorbed by the

874 body, due to the potential variables previously outlined. A review of the health promoting

875 properties of broccoli by Ares et al. ${ }^{160}$ concluded that even with high broccoli intake, it is

876 likely to be insufficient to stimulate anticancer effects at doses outlined in clinical studies.

877 Broccoli varieties bred for high glucoraphanin content have showed promise however. It has

878 been observed that doubling the level of glucoraphanin in florets can produce a three-fold

879 increase in sulforaphane metabolites within the bloodstream compared with a standard 880 variety ${ }^{155}$. This is supported by some excellent and rigorous human clinical studies with

881 Beneforté broccoli, and have shown encouraging results ${ }^{161-163}$

882

\section{SUMMARY}

884

Cell and animal studies have shown that ITCs and indoles have strong protective 885 effects against some cancers ${ }^{164}$. Epidemiological evidence also suggests that vegetables 886 containing GSLs are associated with reduced risks of developing cancer, heart disease ${ }^{165}$ and

887 neurodegenerative diseases ${ }^{10}$. These two kinds of studies are measuring very different things 888 however. In vitro and in vivo animal studies often use ITC compounds in isolation and at high 889 doses ${ }^{166}$ measuring only acute effects. Epidemiological research often takes place over 890 several years, and does not account for compounds acting in isolation (i.e. the beneficial 891 effects cannot be wholly attributed to GSLs/ITCs) ${ }^{55}$. Flavonols, anthocyanins and 892 carotenoids are but a few of the other classes present in these crops, and all have similar 893 reported effects attributed to them ${ }^{96,167}$. 
895 depends on the type and abundances of GSLs/ITCs/indoles within tissues. It depends on the 896 environment in which these crops were grown, and their genetic predisposition for producing 897 certain myrosinase breakdown products over others (i.e. ITC: nitrile ratio). It depends on how 898 the crop is stored, prepared and cooked; it even depends on the metabolic genotype of the 899 individual consumer. This therefore means that GSL measurement at harvest, as a proxy for 900 ITCs/indoles at the time of consumption is extremely tenuous. It makes suggesting how much 901 Brassicaceae should be consumed difficult and filled with caveats that are specific to the 902 species in question and the person consuming it.

903 In order to breed new Brassicaceae varieties with enhanced health benefits, the 904 concentrations and relative myrosinase hydrolysis product abundances must be considered ${ }^{75}$. 905 The literature is plentiful in studies analysing and reporting GSL concentrations, but is 906 lacking in corresponding ITC, nitrile and indole measurements. The predominant reason for 907 this is that these compounds are difficult to extract, identify and quantify, due to their 908 volatile/unstable nature and reactivity ${ }^{168}$. Simple methods have now been developed 909 however, which give robust and informative results ${ }^{98,169}$. While the extraction methods take 910 longer than a crude methanol GSL extraction, it is possible to analyse ITCs/nitriles easily by 911 GC-MS. The information about these compounds will be vital to breeders in making 912 informed selections for any possible health benefits. GSLs are a convenient proxy 913 measurement for the types of breakdown products, but are not in-and-of themselves a good 914 indicator of ITC:nitrile ratios, total abundances, or myrosinase activity.

915 In conclusion, the future of breeding for enhanced GSL/ITC Brassicaceae crops is 916 positive due to the abundance of phenotypic variation available for selection by breeders, and 917 the increased interest in developing health-beneficial products for the consumer. Consumers 918 themselves are actively looking for such products, and are more aware about the long-term 
919 effects of bad dietary habits ${ }^{170}$. As the development of Beneforté broccoli has demonstrated,

920 breeding in this way is achievable for commercial Brassicaceae crops, but must be done in a

921 holistic way which accounts for every stage of varietal development, commercial production,

922 agronomic, and environmental factors - as well as the tastes, preferences and genotypes of

923 the end consumer ${ }^{75}$. This may take decades to achieve, but a roadmap has been established.

924

925

\section{References}

926

(1) Choi, S.-H.; Park, S.; Lim, Y. P.; Kim, S.-J.; Park, J.-T.; An, G. Metabolite profiles of glucosinolates in

927

928

929

(2) Verkerk, R.; Schreiner, M.; Krumbein, A.; Ciska, E.; Holst, B.; Rowland, I.; De Schrijver, R.; Hansen,

930

931

932

933

(3) Grubb, C. D.; Abel, S. Glucosinolate metabolism and its control. Trends Plant Sci. 2006, 11, 89-100.

934 cabbage varieties (Brassica oleracea var. capitata) by season, color, and tissue position. Hortic.

935

936 M.; Gerhauser, C.; Mithen, R.; Dekker, M. Glucosinolates in Brassica vegetables: The influence of the food supply chain on intake, bioavailability and human health. Mol. Nutr. Food Res. 2009, 53, S219-

(7) Moreno, D. A.; Carvajal, M.; López-Berenguer, C.; García-Viguera, C. Chemical and biological characterisation of nutraceutical compounds of broccoli. J. Pharm. Biomed. Anal. 2006, 41, 1508-1522. Higdon, J. V; Delage, B.; Williams, D. E.; Dashwood, R. H. Cruciferous vegetables and human cancer

(10) Giacoppo, S.; Galuppo, M.; Montaut, S.; Iori, R.; Rollin, P.; Bramanti, P.; Mazzon, E. An overview on neuroprotective effects of isothiocyanates for the treatment of neurodegenerative diseases. Fitoterapia 2015, 106, 12-21. content in Brassicaceae sprouts. J. Agric. Food Chem. 2014, 62, 1881-1889. 
(12) Rekhy, R.; McConchie, R. Promoting consumption of fruit and vegetables for better health. Have campaigns delivered on the goals? Appetite 2014, 79, 113-123.

(13) Jones, R. B.; Faragher, J. D.; Winkler, S. A review of the influence of postharvest treatments on quality and glucosinolate content in broccoli (Brassica oleracea var. italica) heads. Postharvest Biol. Technol. 2006, 41, 1-8.

960

(14) Rybarczyk-Plonska, A.; Hagen, S. F.; Borge, G. I. A.; Bengtsson, G. B.; Hansen, M. K.; Wold, A.-B.

(15) Pérez-Balibrea, S.; Moreno, D. A.; García-Viguera, C. Glucosinolates in broccoli sprouts (Brassica

(16) Mølmann, J. A. B.; Steindal, A. L. H.; Bengtsson, G. B.; Seljåsen, R.; Lea, P.; Skaret, J.; Johansen, T. J. oleracea var. italica) as conditioned by sulphate supply during germination. J. Food Sci. 2010, 75, C673-C677.

970

971

972

(20) Sarikamis, G.; Marquez, J.; MacCormack, R.; Bennett, R. N.; Roberts, J.; Mithen, R. High glucosinolate

(21) Schonhof, I.; Krumbein, A.; Brückner, B.; Bruckner, B. Genotypic effects on glucosinolates and sensory

(22) Schreiner, M. C.; Peters, P. J.; Krumbein, A. B. Glucosinolates in mixed-packaged mini broccoli and mini cauliflower under modified atmosphere. J. Agric. Food Chem. 2006, 54, 2218-2222.

17) Brown, A. F.; Yousef, G. G.; Jeffrey, E. H.; Klein, B. P.; Wallig, M. A.; Kushad, M. M.; Juvik, J. A. Glucosinolate profiles in broccoli: Variation in levels and implications in breeding for cancer chemoprotection. J. Am. Soc. Hortic. Sci. 2002, 127, 807-813.

Deng, Q.; Zinoviadou, K. G.; Galanakis, C. M.; Orlien, V.; Grimi, N.; Vorobiev, E.; Lebovka, N.; Barba, F. J. The Effects of Conventional and Non-conventional Processing on Glucosinolates and Its Derived Forms, Isothiocyanates: Extraction, Degradation, and Applications. Food Eng. Rev. 2015, 7, $357-381$.

19) Carlson, D. G.; Daxenbichler, M. E.; Van Etten, C. H.; Kwolek, W. F.; Williams, P. H. Glucosinolates in Crucifer Vegetables - Broccoli, Brussels-Sprouts, Cauliflower, Collards, Kale, Mustard Greens, and Kohlrabi. J. Am. Soc. Hortic. Sci. 1987, 112, 173-178. broccoli: a delivery system for sulforaphane. Mol. Breed. 2006, 18, 219-228. properties of broccoli and cauliflower. Food/Nahrung 2004, 48, 25-33.

Traka, M. H.; Saha, S.; Huseby, S.; Kopriva, S.; Walley, P. G.; Barker, G. C.; Moore, J.; Mero, G.; van den Bosch, F.; Constant, H.; Kelly, L.; Schepers, H.; Boddupalli, S.; Mithen, R. F. Genetic regulation of glucoraphanin accumulation in Beneforté broccoli. New Phytol. 2013, 198, 1085-1095.

Zasada, I. A.; Ferris, H. Nematode suppression with brassicaceous amendments: application based upon glucosinolate profiles. Soil Biol. Biochem. 2004, 36, 1017-1024.

5) Charron, C. S.; Saxton, A. M.; Sams, C. E. Relationship of climate and genotype to seasonal variation in the glucosinolate-myrosinase system. I. Glucosinolate content in ten cultivars of Brassica oleracea grown in fall and spring seasons. J. Sci. Food Agric. 2005, 85, 671-681.

Jeffery, E. H.; Brown, A. F.; Kurilich, A. C.; Keck, A. S.; Matusheski, N.; Klein, B. P.; Juvik, J. A. Variation in content of bioactive components in broccoli. J. Food Compos. Anal. 2003, 16, 323-330. 
(27) Kushad, M. M.; Brown, A. F.; Kurilich, A. C.; Juvik, J. A.; Klein, B. P.; Wallig, M. A.; Jeffery, E. H. Variation of glucosinolates in vegetable crops of Brassica oleracea. J. Agric. Food Chem. 1999, 47, 1541-1548.

(28) Latte, K. P.; Appel, K. E.; Lampen, A. Health benefits and possible risks of broccoli - An overview. Food Chem. Toxicol. 2011, 49, 3287-3309.

1000

(29) Jones, R. B.; Frisina, C. L.; Winkler, S.; Imsic, M.; Tomkins, R. B. Cooking method significantly

1001

1002 effects glucosinolate content and sulforaphane production in broccoli florets. Food Chem. 2010, 123, $237-242$.

1003

(30) Mahn, A.; Reyes, A. An overview of health-promoting compounds of broccoli (Brassica oleracea var.

1004 italica) and the effect of processing. Food Sci. Technol. Int. 2012, 18, 503-514.

1005

(31) Mithen, R. F.; Dekker, M.; Verkerk, R.; Rabot, S.; Johnson, I. T. The nutritional significance,

1006

1007

1008

(32) Tiedink, H. G. M.; Davies, J. A. R.; van Broekhoven, L. W.; van der Kamp, H. J.; Jongen, W. M. F.

1009

1010

1011

(33) Oliviero, T.; Verkerk, R.; Dekker, M. Effect of water content and temperature on glucosinolate

1012

1013

(34) Pellegrini, N.; Chiavaro, E.; Gardana, C.; Mazzeo, T.; Contino, D.; Gallo, M.; Riso, P.; Fogliano, V.;

1014

1015

1016

(35) Smith, T. K.; Lund, E. K.; Clarke, R. G.; Bennett, R. N.; Johnson, I. T. Effects of Brussels sprout juice

(36) Schreiner, M.; Krumbein, A.; Ruppel, S. Interaction between plants and bacteria: glucosinolates and 1020

1021

1022

(37) Cartea, M. E.; Velasco, P.; Obregon, S.; Padilla, G.; de Haro, A. Seasonal variation in glucosinolate 1023

1024

1025

1026

1027

1028

1029

1030

(40) Oerlemans, K.; Barrett, D. M.; Suades, C. B.; Verkerk, R.; Dekker, M. Thermal degradation of 1031

1032

(41) Verkerk, R.; Dekker, M. Glucosinolates and myrosinase activity in red cabbage (Brassica oleracea L.

1033

1034

(38) Dekker, M.; Verkerk, R.; Jongen, W. M. F. Predictive modelling of health aspects in the food production chain: a case study on glucosinolates in cabbage. Trends Food Sci. Technol. 2000, 11, 174181.

(39) Volden, J.; Borge, G. I. A.; Bengtsson, G. B.; Hansen, M.; Thygesen, I. E.; Wicklund, T. Effect of thermal treatment on glucosinolates and antioxidant-related parameters in red cabbage (Brassica oleracea L. ssp. capitata f. rubra) Food Chem. 2008, 109, 595-605. glucosinolates in red cabbage. Food Chem. 2006, 95, 19-29.

var. Capitata f. rubra DC.) after various microwave treatments. J. Agric. Food Chem. 2004, 52, 73187323. 
(42) Volden, J.; Borge, G. I. A.; Hansen, M.; Wicklund, T.; Bengtsson, G. B. Processing (blanching, boiling, steaming) effects on the content of glucosinolates and antioxidant-related parameters in cauliflower (Brassica oleracea L. ssp. botrytis). LWT - Food Sci. Technol. 2009, 42, 63-73.

(43) Kang, J. Y.; Ibrahim, K. E.; Juvik, J. A.; Kim, D. H.; Kang, W. J. Genetic and environmental variation of glucosinolate content in Chinese cabbage. Hortscience 2006, 41, 1382-1385.

1040

(44) Kim, J. K.; Chu, S. M.; Kim, S. J.; Lee, D. J.; Lee, S. Y.; Lim, S. H.; Ha, S.-H.; Kweon, S. J.; Cho, H. S. Variation of glucosinolates in vegetable crops of Brassica rapa L. ssp pekinensis. Food Chem. 2010, $119,423-428$.

1043

(45) Baek, S.-A.; Jung, Y.-H.; Lim, S.-H.; Park, S. U.; Kim, J. K. Metabolic Profiling in Chinese Cabbage (Brassica rapa L. subsp. pekinensis) Cultivars Reveals that Glucosinolate Content Is Correlated with Carotenoid Content. J. Agric. Food Chem. 2016, 64, 4426-4434.

(46) Qian, H.; Liu, T.; Deng, M.; Miao, H.; Cai, C.; Shen, W.; Wang, Q. Effects of light quality on main

(47) Guo, R.; Huang, Z.; Deng, Y.; Chen, X.; XuHan, X.; Lai, Z. Comparative Transcriptome Analyses Reveal a Special Glucosinolate Metabolism Mechanism in Brassica alboglabra Sprouts. Front. Plant Sci. 2016, 7, 1497.

1052

(48) Schreiner, M.; Beyene, B.; Krumbein, A.; Stützel, H. Ontogenetic Changes of 2-Propenyl and 3Indolylmethyl Glucosinolates in Brassica carinata Leaves as Affected by Water Supply. J. Agric. Food Chem. 2009, 57, 7259-7263.

1055

(49) Bellostas, N.; Sørensen, J. C.; Sørensen, H. Profiling glucosinolates in vegetative and reproductive tissues of four Brassica species of the U-triangle for their biofumigation potential. J. Sci. Food Agric. 2007, 87, 1586-1594.

(50) Abe, K.; Kido, S.; Maeda, T.; Kami, D.; Matsuura, H.; Shimura, H.; Suzuki, T. Glucosinolate profiles in Cardamine fauriei and effect of light quality on glucosinolate concentration. Sci. Hortic. (Amsterdam). 2015, 189, 12-16.

1061

(51) Avato, P.; Argentieri, M. P. Brassicaceae: a rich source of health improving phytochemicals. Phytochem. Rev. 2015, 14, 1019-1033.

1064

1065

1066

1067

1068

(54) Yábar, E.; Pedreschi, R.; Chirinos, R.; Campos, D. Glucosinolate content and myrosinase activity drying. Food Chem. 2011, 127, 1576-1583.

5) Possenti, M.; Baima, S.; Raffo, A.; Durazzo, A.; Giusti, A. M.; Natella, F. In Glucosinolates; Springer International Publishing: Cham, 2016; pp. 1-46.

Förster, N.; Ulrichs, C.; Schreiner, M.; Müller, C. T.; Mewis, I. Development of a reliable extraction and quantification method for glucosinolates in Moringa oleifera. Food Chem. 2015, 166, 456-464. 
(57) Doerr, B.; Wade, K. L.; Stephenson, K. K.; Reed, S. B.; Fahey, J. W. Cultivar Effect on Moringa oleifera Glucosinolate Content and Taste: A Pilot Study. Ecol. Food Nutr. 2009, 48, 199-211.

1077

1078

1079

1080

1081

1082

1083

1084

1085

1086

1087

1088

1089

1090

1091

1092

1093

1094

1095

1096

1097

1098

1099

1100

1101

1102

1103

1104

1105

1106

1107

1108

1109

1110

1111

1112

1113

1114
(58) Förster, N.; Ulrichs, C.; Schreiner, M.; Arndt, N.; Schmidt, R.; Mewis, I. Ecotype Variability in Growth and Secondary Metabolite Profile in Moringa oleifera: Impact of Sulfur and Water Availability. J. Agric. Food Chem. 2015, 63, 2852-2861.

(59) Cosme, M.; Franken, P.; Mewis, I.; Baldermann, S.; Wurst, S. Arbuscular mycorrhizal fungi affect glucosinolate and mineral element composition in leaves of Moringa oleifera. Mycorrhiza 2014, 24, $565-570$.

(60) Bennett, R. N.; Mellon, F. A.; Foidl, N.; Pratt, J. H.; Dupont, M. S.; Perkins, L.; Kroon, P. A. Profiling Glucosinolates and Phenolics in Vegetative and Reproductive Tissues of the Multi-Purpose Trees Moringa oleifera L. (Horseradish Tree) and Moringa stenopetala L. and Marketing and Enterprise Program for Natural Resource-Based Products, Malawi Agr. J. Agric. Food Chem. 2003, 51, 35463553.

(61) Hanlon, P. R.; Webber, D. M.; Barnes, D. M. Aqueous extract from spanish black radish (Raphanus sativus L. Var. niger) induces detoxification enzymes in the HepG2 human hepatoma cell line. J. Agric. Food Chem. 2007, 55, 6439-6446.

(62) Bell, L.; Oruna-Concha, M. J.; Wagstaff, C. Identification and quantification of glucosinolate and flavonol compounds in rocket salad (Eruca sativa, Eruca vesicaria and Diplotaxis tenuifolia) by LCMS: highlighting the potential for improving nutritional value of rocket crops. Food Chem. 2015, 172, $852-861$.

(63) Jin, J.; Koroleva, O. A.; Gibson, T.; Swanston, J.; Magan, J.; Zhang, Y.; Rowland, I. R.; Wagstaff, C. Analysis of Phytochemical Composition and Chemoprotective Capacity of Rocket (Eruca sativa and Diplotaxis tenuifolia) Leafy Salad Following Cultivation in Different Environments. J. Agric. Food Chem. 2009, 57, 5227-5234.

(64) Selma, M. V; Martinez-Sanchez, A.; Allende, A.; Ros, M.; Hernandez, M. T.; Gil, M. I. Impact of Organic Soil Amendments on Phytochemicals and Microbial Quality of Rocket Leaves (Eruca sativa). J. Agric. Food Chem. 2010, 58, 8331-8337.

(65) Taranto, F.; Francese, G.; Di Dato, F.; D’Alessandro, A.; Greco, B.; Onofaro Sanajà, V.; Pentangelo, A.; Mennella, G.; Tripodi, P. Leaf Metabolic, Genetic, and Morphophysiological Profiles of Cultivated and Wild Rocket Salad (Eruca and Diplotaxis Spp.). J. Agric. Food Chem. 2016, 64, 5824-5836.

(66) Cataldi, T. R. I.; Rubino, A.; Lelario, F.; Bufo, S. A. Naturally occuring glucosinolates in plant extracts of rocket salad (Eruca sativa L.) identified by liquid chromatography coupled with negative ion electrospray ionization and quadrupole ion-trap mass spectrometry. Rapid Commun. Mass Spectrom. 2007, 21, 2374-2388.

(67) Agerbirk, N.; Olsen, C. E. Glucosinolate structures in evolution. Phytochemistry 2012, 77, 16-45.

(68) Johansen, T. J.; Hagen, S. F.; Bengtsson, G. B.; Mølmann, J. A. B. Growth temperature affects sensory quality and contents of glucosinolates, vitamin $\mathrm{C}$ and sugars in swede roots (Brassica napus L. ssp. rapifera Metzg.). Food Chem. 2016, 196, 228-235.

(69) Omondi, E. O.; Engels, C.; Nambafu, G.; Schreiner, M.; Neugart, S.; Abukutsa-Onyango, M.; Winkelmann, T. Nutritional compound analysis and morphological characterization of spider plant 
Clarke, D. B. Glucosinolates, structures and analysis in food. Anal. Methods 2010, 2, 310-325.

(71) Giallourou, N.; Oruna-Concha, M. J.; Harbourne, N. Effects of domestic processing methods on the phytochemical content of watercress (Nasturtium officinale). Food Chem. 2016, 212, 411-419.

1120

(72) Anonymous. ICRISAT Happenings. February 2015, pp. 1-2.

1121

(73) Davis, D. R.; Epp, M. D.; Riordan, H. D. Changes in USDA food composition data for 43 garden crops, 1950 to 1999. J. Am. Coll. Nutr. 2004, 23, 669-682.

1123

(74) Brown, J.; Caligari, Peter, D.; Campos, H. Plant Breeding; 2nd ed.; Wiley-Blackwell, 2014.

1124

(75) Goldman, I. L. The Future of Breeding Vegetables with Human Health Functionality: Realities, Challenges, and Opportunities. Hortscience 2014, 49, 133-137.

1125

(76) Bell, L.; Methven, L.; Signore, A.; Jose Oruna-Concha, M.; Wagstaff, C. Analysis of Seven Salad

(77) Ishida, M.; Hara, M.; Fukino, N.; Kakizaki, T.; Morimitsu, Y. Glucosinolate metabolism, functionality and breeding for the improvement of Brassicaceae vegetables. Breed. Sci. 2014, 64, 48-59.

(78) Tian, M.; Xu, X.; Liu, Y.; Xie, L.; Pan, S. Effect of Se treatment on glucosinolate metabolism and health-promoting compounds in the broccoli sprouts of three cultivars. Food Chem. 2016, 190, 374380 .

(79) Farnham, M. W.; Simon, P. W.; Stommel, J. R. Improved phytonutrient content through plant genetic improvement. Nutr. Rev. 1999, 57, S19-S26.

(80) Moose, S. P.; Mumm, R. H. Molecular plant breeding as the foundation for 21st century crop improvement. Plant Physiol. 2008, 147, 969-977.

(81) Casagrande, S. S.; Wang, Y.; Anderson, C.; Gary, T. L. Have Americans increased their fruit and vegetable intake? The trends between 1988 and 2002. Am. J. Prev. Med. 2007, 32, 257-263.

1139

(82) Aune, D.; Giovannucci, E.; Boffetta, P.; Fadnes, L. T.; Keum, N.; Norat, T.; Greenwood, D. C.; Riboli,

(83) Kopsell, D. A.; Barickman, T. C.; Sams, C. E.; McElroy, J. S. Influence of nitrogen and sulfur on biomass production and carotenoid and glucosinolate concentrations in watercress (Nasturtium officinale R. Br.). J. Agric. Food Chem. 2007, 55, 10628-10634.

(84) Vaughn, S. F.; Berhow, M. A. Glucosinolate hydrolysis products from various plant sources: $\mathrm{pH}$ effects, isolation, and purification. Ind. Crops Prod. 2005, 21, 193-202.

(85) Sun, B.; Liu, N.; Zhao, Y.; Yan, H.; Wang, Q. Variation of glucosinolates in three edible parts of Chinese kale (Brassica alboglabra Bailey) varieties. Food Chem. 2011, 124, 941-947.

(86) Schreiner, M. Vegetable crop management strategies to increase the quantity of phytochemicals. Eur. J. Nutr. 2005, 44, 85-94. broccoli (Brassica oleracea var. italica) florets from China. Food Chem. 2012, 133, 735-741.

(88) Balasubramanian, S.; Schwartz, C.; Singh, A.; Warthmann, N.; Kim, M. C.; Maloof, J. N.; Loudet, O.; 
Trainer, G. T.; Dabi, T.; Borevitz, J. O.; Chory, J.; Weigel, D. QTL Mapping in New Arabidopsis

(89) Aljanabi, S. Genomics and plant breeding. Biotechnol. Annu. Rev. 2001, 7, 195-238.

1158

(90) Li, G.; Riaz, A.; Goyal, S.; Abel, S.; Quiros, C. F. Inheritance of three major genes involved in the synthesis of aliphatic glucosinolates in Brassica oleracea. J. Am. Soc. Hortic. Sci. 2001, 126, 427-431.

1160

(91) Frerigmann, H.; Piślewska-Bednarek, M.; Sánchez-Vallet, A.; Molina, A.; Glawischnig, E.;

1161

1162

1163

1164

(92) Kim, J. H.; Jander, G. Myzus persicae (green peach aphid) feeding on Arabidopsis induces the

(93) Mikkelsen, M. D.; Petersen, B. L.; Glawischnig, E.; Jensen, A. B.; Andreasson, E.; Halkier, B. A.

(94) Jensen, L. M.; Halkier, B. A.; Burow, M. How to discover a metabolic pathway? An update on gene

(95) Ku, K. M.; Jeffery, E. H.; Juvik, J. A. Optimization of methyl jasmonate application to broccoli florets

(96) Bell, L.; Wagstaff, C. Glucosinolates, Myrosinase Hydrolysis Products, and Flavonols Found in Rocket

(97) Witzel, K.; Neugart, S.; Ruppel, S.; Schreiner, M.; Wiesner, M.; Baldermann, S. Recent progress in the

(98) Bell, L.; Yahya, H. N.; Oloyede, O. O.; Methven, L.; Wagstaff, C. Changes In Rocket Salad

(100) Chiang, W. C. K.; Pusateri, D. J.; Leitz, R. E. A. Gas chromatography mass spectrometry method for the

(102) Drewnowski, A.; Gomez-Carneros, C. Bitter taste, phytonutrients, and the consumer: a review. Am. J.

(103) Steinmetz, K. A.; Potter, J. D. Vegetables, Fruit, and Cancer .2. Mechanisms. Cancer Causes Control

(104) Nishie, K.; Daxenbichler, M. E. Toxicology of glucosinolates, related compounds (nitriles, R-goitrin, 
feeds. J. Agric. Food Chem. 1969, 17, 483-491.

1196
(106) Angelino, D.; Dosz, E. B.; Sun, J.; Hoeflinger, J. L.; Van Tassell, M. L.; Chen, P.; Harnly, J. M.; Miller, M. J.; Jeffery, E. H. Myrosinase-dependent and -independent formation and control of isothiocyanate products of glucosinolate hydrolysis. Front. Plant Sci. 2015, 6.

(107) Bjorkman, M.; Klingen, I.; Birch, A. N. E.; Bones, A. M.; Bruce, T. J. A.; Johansen, T. J.; Meadow, R.; Molmann, J.; Seljasen, R.; Smart, L. E.; Stewart, D. Phytochemicals of Brassicaceae in plant protection and human health - Influences of climate, environment and agronomic practice. Phytochemistry 2011, $72,538-556$.

(108) Sodhi, Y. S.; Mukhopadhyay, A.; Arumugam, N.; Verma, J. K.; Gupta, V.; Pental, D.; Pradhan, A. K. Genetic analysis of total glucosinolate in crosses involving a high glucosinolate Indian variety and a low glucosinolate line of Brassica juncea. Plant Breed. 2002, 121, 508-511.

(109) Aires, A.; Rosa, E.; Carvalho, R. Effect of nitrogen and sulfur fertilization on glucosinolates in the leaves and roots of broccoli sprouts (Brassica oleracea var. italica). J. Sci. Food Agric. 2006, 86, 15121516.

(110) Hanschen, F. S.; Schreiner, M. Isothiocyanates, Nitriles, and Epithionitriles from Glucosinolates Are Affected by Genotype and Developmental Stage in Brassica oleracea Varieties. Front. Plant Sci. 2017, 8,1095 .

(111) Engelen-Eigles, G.; Holden, G.; Cohen, J. D.; Gardner, G. The effect of temperature, photoperiod, and light quality on gluconasturtiin concentration in watercress (Nasturtium officinale R. Br.). J. Agric. Food Chem. 2006, 54, 328-334.

(112) Guo, L.; Yang, R.; Wang, Z.; Guo, Q.; Gu, Z. Glucoraphanin, sulforaphane and myrosinase activity in germinating broccoli sprouts as affected by growth temperature and plant organs. J. Funct. Foods 2014, 9, 70-77.

(113) Winkler, S.; Faragher, J.; Franz, P.; Imsic, M.; Jones, R. Glucoraphanin and flavonoid levels remain stable during simulated transport and marketing of broccoli (Brassica oleracea var. italica) heads. Postharvest Biol. Technol. 2007, 43, 89-94.

(114) Wang, Y.; Xu, W.; Yan, X.; Wang, Y. Glucosinolate content and related gene expression in response to enhanced UV-B radiation in Arabidopsis. African J. Biotechnol. 2011, 10, 6481-6491.

(115) Martínez-Ballesta, M. D. C.; Moreno, D. A.; Carvajal, M. The physiological importance of glucosinolates on plant response to abiotic stress in Brassica. Int. J. Mol. Sci. 2013, 14.

(116) Moreira-Rodríguez, M.; Nair, V.; Benavides, J.; Cisneros-Zevallos, L.; Jacobo-Velázquez, D. UVA, UVB Light Doses and Harvesting Time Differentially Tailor Glucosinolate and Phenolic Profiles in Broccoli Sprouts. Molecules 2017, 22, 1065.

(117) Kim, Y. B.; Chun, J.-H.; Kim, H. R.; Kim, S.-J.; Lim, Y. P.; Park, S. U. Variation of Glucosinolate Accumulation and Gene Expression of Transcription Factors at Different Stages of Chinese Cabbage Seedlings under Light and Dark Conditions. Nat. Prod. Commun. 2014, 9, 533-537.

(118) Huseby, S.; Koprivova, A.; Lee, B.-R.; Saha, S.; Mithen, R.; Wold, A.-B.; Bengtsson, G. B.; Kopriva, S. Diurnal and light regulation of sulphur assimilation and glucosinolate biosynthesis in Arabidopsis. $J$. Exp. Bot. 2013, 64, 1039-1048.

(119) Antonious, G. F.; Kasperbauer, M. J.; Byers, M. E. Light Reflected from Colored Mulches to Growing 
Turnip Leaves Affects Glucosinolate and Sugar Contents of Edible Roots. Photochem. Photobiol. 1996, 64, 605-610.

(120) Kopsell, D. A.; Sams, C. E. Increases in Shoot Tissue Pigments, Glucosinolates, and Mineral Elements in Sprouting Broccoli after Exposure to Short-duration Blue Light from Light Emitting Diodes. J. Am. Soc. Hortic. Sci. 2013, 138, 31-37.

(121) Schonhof, I.; Kläring, H.-P.; Krumbein, A.; Claußen, W.; Schreiner, M. Effect of temperature increase

(122) Borpatragohain, P.; Rose, T. J.; King, G. J. Fire and Brimstone: Molecular Interactions between Sulfur

(123) Li, S.; Schonhof, I.; Krumbein, A.; Li, L.; Stützel, H.; Schreiner, M. Glucosinolate Concentration in

(126) Scheuner, E. T.; Krumbein, A.; Schonhof, I.; Schreiner, M. Increasing the alkyl glucosinolate level in

(128) Bates, B.; Lennox, A.; Prentice, A.; Bates, C.; Swan, G. National Diet and Nutrition Survey Headline

(129) Schiavon, M.; Berto, C.; Malagoli, M.; Trentin, A.; Sambo, P.; Dall’Acqua, S.; Pilon-Smits, E. A. H. Turnip (Brassica rapa ssp. rapifera L.) Roots as Affected by Nitrogen and Sulfur Supply. J. Agric. Food Chem. 2007, 55, 8452-8457.

(124) Schonhof, I.; Blankenburg, D.; Muller, S.; Krumbein, A. Sulfur and nitrogen supply influence growth, product appearance, and glucosinolate concentration of broccoli. J. Plant Nutr. Soil Sci. Fur Pflanzenernahrung Und Bodenkd. 2007, 170, 65-72.

(125) Hirai, M. Y.; Yano, M.; Goodenowe, D. B.; Kanaya, S.; Kimura, T.; Awazuhara, M.; Arita, M.; Fujiwara, T.; Saito, K. Integration of transcriptomics and metabolomics for understanding of global responses to nutritional stresses in Arabidopsis thaliana. Proc. Natl. Acad. Sci. U. S. A. 2004, 101, 10205-10210. Broccoli by leafstalk infusion of methionine. J. Appl. Bot. food Qual. 2005, 79, 175-178.

Piekarska, A.; Kołodziejski, D.; Pilipczuk, T.; Bodnar, M.; Konieczka, P.; Kusznierewicz, B.; Hanschen, F. S.; Schreiner, M.; Cyprys, J.; Groszewska, M.; Namieśnik, J.; Bartoszek, A. The influence of selenium addition during germination of Brassica seeds on health-promoting potential of sprouts. Int. J. Food Sci. Nutr. 2014, 65, 692-702. results from Years 1, 2 and 3 (combined) of the Rolling Programme (2008/2009 - 2010/11); 2012. Selenium Biofortification in Radish Enhances Nutritional Quality via Accumulation of MethylSelenocysteine and Promotion of Transcripts and Metabolites Related to Glucosinolates, Phenolics, and Amino Acids. Front. Plant Sci. 2016, 7, 1371.

(130) Robbins, R. J.; Keck, A.-S.; Banuelos, G.; Finley, J. W. Cultivation Conditions and Selenium Fertilization Alter the Phenolic Profile, Glucosinolate, and Sulforaphane Content of Broccoli. J. Med. Food 2005, 8, 204-214.

(131) Palaniswamy, U. R.; Mcavoy, R. J.; Bible, B. B.; Stuart, J. D. Ontogenic Variations of Ascorbic Acid and Phenethyl Isothiocyanate Concentrations in Watercress (Nasturtium officinale R.Br.) Leaves. J. Agric. Food Chem. 2003, 51, 5504-5509.

Hansen, M.; Moller, P.; Sorensen, H.; Detrejo, M. C. Glucosinolates in broccoli stored under controlledatmosphere. J. Am. Soc. Hortic. Sci. 1995, 120, 1069-1074. 
(133) Fernández-León, M. F. F.; Fernández-León, A. M. M.; Lozano, M.; Ayuso, M. C. C.; González-Gómez, D. Altered commercial controlled atmosphere storage conditions for 'Parhenon' broccoli plants (Brassica oleracea L. var. italica). Influence on the outer quality parameters and on the healthpromoting compounds. LWT - Food Sci. Technol. 2013, 50, 665-672.

(134) Rodrigues, A. S.; Rosa, E. A. Effect of post-harvest treatments on the level of glucosinolates in broccoli. J. Sci. Food Agric. 1999, 79, 1028-1032.

(135) Mewis, I.; Schreiner, M.; Nguyen, C. N.; Krumbein, A.; Ulrichs, C.; Lohse, M.; Zrenner, R. UV-B irradiation changes specifically the secondary metabolite profile in broccoli sprouts: induced signaling overlaps with defense response to biotic stressors. Plant Cell Physiol. 2012, 53, 1546-1560.

(136) Guillén, S.; Mir-Bel, J.; Oria, R.; Salvador, M. L. Influence of cooking conditions on organoleptic and health-related properties of artichokes, green beans, broccoli and carrots. Food Chem. 2017, 217, 209216.

(137) West, L. G.; Meyer, K. A.; Balch, B. A.; Rossi, F. J.; Schultz, M. R.; Haas, G. W. Glucoraphanin and 4hydroxyglucobrassicin contents in seeds of 59 cultivars of broccoli, raab, kohlrabi, radish, cauliflower, brussels sprouts, kale, and cabbage. J. Agric. Food Chem. 2004, 52, 916-926.

(138) McFarlane, T.; Pliner, P. Increasing Willingness to Taste Novel Foods: Effects of Nutrition and Taste Information. Appetite 1997, 28, 227-238.

(139) Nugrahedi, P. Y.; Hantoro, I.; Verkerk, R.; Dekker, M.; Steenbekkers, B. Practices and health perception of preparation of Brassica vegetables: translating survey data to technological and nutritional implications. Int. J. Food Sci. Nutr. 2015, 66, 633-641.

(140) Palermo, M.; Pellegrini, N.; Fogliano, V. The effect of cooking on the phytochemical content of vegetables. J. Sci. Food Agric. 2014, 94, 1057-1070.

(141) Gliszczyńska-Świgło, A.; Ciska, E.; Pawlak-Lemańska, K.; Chmielewski, J.; Borkowski, T.; Tyrakowska, B. Changes in the content of health-promoting compounds and antioxidant activity of broccoli after domestic processing. Food Addit. Contam. 2006, 23, 1088-1098.

(142) Girgin, N.; El, S. N. Effects of cooking on in vitro sinigrin bioaccessibility, total phenols, antioxidant and antimutagenic activity of cauliflower (Brassica oleraceae L. var. Botrytis). J. Food Compos. Anal. 2015, 37, 119-127.

(143) Ciska, E.; Kozłowska, H. The effect of cooking on the glucosinolates content in white cabbage. Eur. Food Res. Technol. 2001, 212, 582-587.

(144) Matusheski, N. V.; Juvik, J. A.; Jeffery, E. H. Heating decreases epithiospecifier protein activity and increases sulforaphane formation in broccoli. Phytochemistry 2004, 65, 1273-1281.

(145) Ippoushi, K.; Ueda, H.; Takeuchi, A. Milk prevents the degradation of daikon (Raphanus sativus L.) isothiocyanate and enhances its absorption in rats. Food Chem. 2014, 161, 176-180.

(146) Bell, L.; Methven, L.; Wagstaff, C. The influence of phytochemical composition and resulting sensory attributes on preference for salad rocket (Eruca sativa) accessions by consumers of varying TAS2R38 diplotype. Food Chem. 2017, 222, 6-17.

(147) Ley, J. P. Masking Bitter Taste by Molecules. Chemosens. Percept. 2008, 1, 58-77.

(148) Pohjanheimo, T. A.; Sandell, M. A. Headspace volatiles contributing to flavour and consumer liking of wellness beverages. Food Chem. 2009, 115, 843-851. 
(149) Bonnesen, C.; Eggleston, I. M.; Hayes, J. D. Dietary indoles and isothiocyanates that are generated from cruciferous vegetables can both stimulate apoptosis and confer protection against DNA damage in human colon cell lines. Cancer Res. 2001, 61, 6120-6130.

(150) Wu, X.; Zhou, Q. H.; Xu, K. Are isothiocyanates potential anti-cancer drugs? Acta Pharmacol. Sin. 2009, 30, 501-512.

(151) Kim, M. K.; Park, J. H. Y. Cruciferous vegetable intake and the risk of human cancer: Epidemiological evidence. Proc. Nutr. Soc. 2009, 68, 103-110.

(152) Morse, M. A.; Eklind, K. I.; Hecht, S. S.; Jordan, K. G.; Choi, C.-I.; Desai, D. H.; Amin, S. G.; Chung, F.-L. Structure-Activity Relationships for Inhibition of 4-(Methylnitrosamino)-1-(3-pyridyl)-1-butanone Lung Tumorigenesis by Arylalkyl Isothiocyanates in A/J Mice. Cancer Res. 1991, 51, 1846-1850.

(153) Kassie, F.; Rabot, S.; Uhl, M.; Huber, W.; Qin, H. M.; Helma, C.; Schulte-Hermann, R.; Knasmuller, S. Chemoprotective effects of garden cress (Lepidium sativum) and its constituents towards 2-amino-3methyl-imidazo[4,5-f]quinoline (IQ)-induced genotoxic effects and colonic preneoplastic lesions. Carcinogenesis 2002, 23, 1155-1161.

(154) Fernando Reyes, L.; Emilio Villarreal, J.; Cisneros-Zevallos, L. The increase in antioxidant capacity after wounding depends on the type of fruit or vegetable tissue. Food Chem. 2007, 101, 1254-1262.

(155) Gasper, A. V; Al-janobi, A.; Smith, J. A.; Bacon, J. R.; Fortun, P.; Atherton, C.; Taylor, M. A.; Hawkey, C. J.; Barrett, D. A.; Mithen, R. F. Glutathione S-transferase M1 polymorphism and metabolism of sulforaphane from standard and high-glucosinolate broccoli. Am. J. Clin. Nutr. 2005, 82, $1283-1291$.

(156) Lampe, J. W. Sulforaphane: from chemoprevention to pancreatic cancer treatment? Gut 2009, 58, 900902.

(157) Bogaards, J. J. P.; Verhagen, H.; Willems, M. I.; Poppel, G. van; Bladeren, P. J. van. Consumption of Brussels sprouts results in elevated $\alpha$-class glutathione S-transferase levels in human blood plasma. Carcinogenesis 1994, 15, 1073-1075.

(158) Houghton, C. A.; Fassett, R. G.; Coombes, J. S. Sulforaphane: Translational research from laboratory bench to clinic. Nutr. Rev. 2013, 71 .

(159) Link, L. B.; Potter, J. D. Raw versus cooked vegetables and cancer risk. Cancer Epidemiol. Biomarkers Prev. 2004, 13, 1422-1435.

(160) Ares, A. M.; Nozal, M. J.; Bernal, J. Extraction, chemical characterization and biological activity determination of broccoli health promoting compounds. J. Chromatogr. A 2013, 1313, 78-95.

(161) Armah, C. N.; Derdemezis, C.; Traka, M. H.; Dainty, J. R.; Doleman, J. F.; Saha, S.; Leung, W.; Potter, J. F.; Lovegrove, J. A.; Mithen, R. F. Diet rich in high glucoraphanin broccoli reduces plasma LDL cholesterol: Evidence from randomised controlled trials. Mol. Nutr. Food Res. 2015, 0, 1-9.

(162) Armah, C. N.; Traka, M. H.; Dainty, J. R.; Defernez, M.; Janssens, A.; Leung, W.; Doleman, J. F.; Potter, J. F.; Mithen, R. F. A diet rich in high-glucoraphanin broccoli interacts with genotype to reduce discordance in plasma metabolite profiles by modulating mitochondrial function. Am. J. Clin. Nutr. 2013, 98, 712-722.

(163) Traka, M.; Gasper, A. V; Melchini, A.; Bacon, J. R.; Needs, P. W.; Frost, V.; Chantry, A.; Jones, A. M. E.; Ortori, C. A.; Barrett, D. A.; Ball, R. Y.; Mills, R. D.; Mithen, R. F. Broccoli Consumption Interacts 
with GSTM1 to Perturb Oncogenic Signalling Pathways in the Prostate. PLoS One 2008, 3.

1356

\section{Figure legends}

1375

1376 Figure 1. A schematic of the most important factors for consideration when breeding for 1377 improved glucosinolate/isothiocyanate profiles of Brassicaceae species.

1379 Figure 2. Molecular structures of isothiocyanates and indole compounds with known health1380 beneficial properties. 


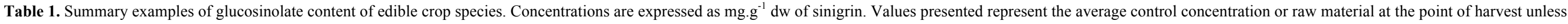
otherwise stated. Values for leaves, sprouts, florets, stems and roots are presented separately.

\begin{tabular}{|c|c|c|c|c|c|c|c|c|c|c|c|c|c|c|c|c|c|c|c|c|c|c|c|c|c|c|}
\hline Common name & Species & 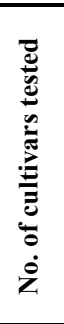 & 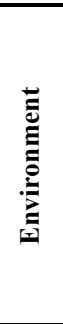 & 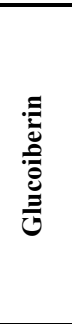 & 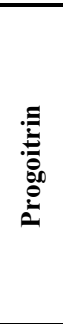 & 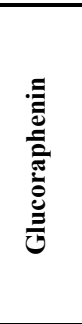 & 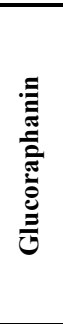 & 部 & 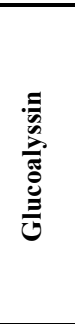 & 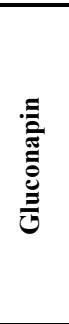 & 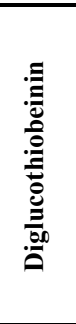 & 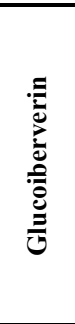 & 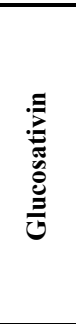 & 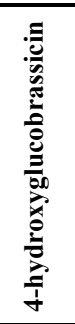 & 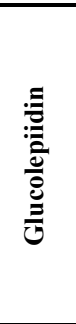 & 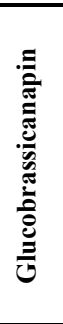 & 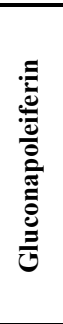 & 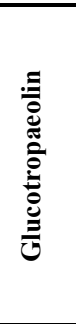 & 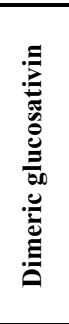 & 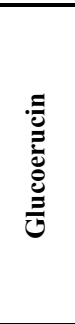 & 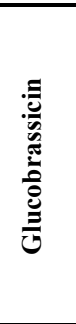 & 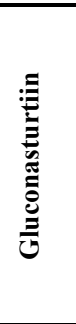 & 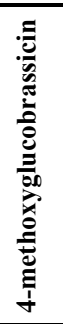 & 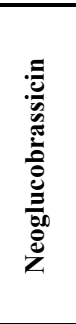 & 苞 & 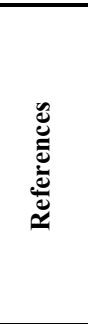 \\
\hline \multicolumn{27}{|l|}{ Leaves } \\
\hline \multirow{4}{*}{ Ezo-wasabi } & Cardamine fauriei & 1 & $\mathrm{H}$ & 13.0 & & & & & & 47.0 & & & & & & & & & & & 3.0 & & & & 63.0 & 50 \\
\hline & $\begin{array}{l}\text { Brassica rapa var. } \\
\text { chinensis }\end{array}$ & 1 & $\mathrm{CE}$ & & nd & & 0.4 & 0.2 & nd & 0.7 & & & & nd & & nd & nd & & & nd & $<0.1$ & $<0.1$ & nd & nd & 1.9 & 36 \\
\hline & & 23 & $\mathrm{~F}$ & & 0.6 & & nd & nd & nd & nd & & & & nd & & nd & nd & & & nd & 0.8 & 1.7 & nd & 0.1 & 3.3 & 43 \\
\hline & & 7 & G & & 0.4 & & nd & $<0.1$ & 0.4 & 1.0 & & & & 0.2 & & nd & nd & & & nd & 0.5 & 0.1 & 0.8 & $<0.1$ & 4.8 & 45 \\
\hline \multirow[t]{4}{*}{ Chinese cabbage } & $\begin{array}{l}\text { Brassica rapa var. } \\
\text { pekinensis }\end{array}$ & 23 & G & & 0.4 & & nd & nd & nd & nd & & & & nd & & nd & nd & & & nd & 0.5 & 2.1 & nd & 0.7 & 3.3 & 43 \\
\hline & & 12 & G & & 0.5 & & 0.1 & $<0.1$ & 0.5 & nd & & & & 0.1 & & 1.4 & 1.0 & & & 0.1 & 0.8 & nd & 1.3 & 0.1 & 5.9 & 44 \\
\hline & & 1 & $?$ & & nd & & nd & nd & nd & nd & & & & nd & & nd & nd & & & nd & 0.5 & 0.2 & 0.6 & $<0.1$ & 1.4 & 31,32 \\
\hline & Average & - & - & & 0.3 & & 0.1 & $<0.1$ & 0.2 & 0.3 & & & & 0.1 & & 0.2 & 0.2 & & & $<0.1$ & 0.5 & 0.7 & 0.5 & 0.2 & 3.4 & \\
\hline \multirow{5}{*}{ Salad rocket } & & 28 & $\mathrm{CE}$ & & nd & $<0.1$ & 0.2 & & $<0.1$ & & $<0.1$ & $<0.1$ & 3.9 & $<0.1$ & $<0.1$ & & & $<0.1$ & 2.2 & 0.2 & & & & & 6.7 & 62 \\
\hline & Eruca sativa & 1 & $\mathrm{CE}$ & & nd & nd & 0.3 & & nd & & 1.4 & 0.7 & 4.2 & nd & nd & & & nd & nd & $<0.1$ & & & & & 6.6 & 63 \\
\hline & & 1 & $\mathrm{CE}$ & & nd & nd & 4.6 & & nd & & nd & nd & 10.8 & nd & nd & & & nd & nd & 2.9 & & & & & 18.3 & 64 \\
\hline & & 21 & G & & 0.8 & nd & 2.8 & & 0.6 & & 6.8 & $\mathrm{nd}$ & 3.3 & nd & nd & & & nd & 9.8 & 5.4 & & & & & 29.5 & 65 \\
\hline & Average & - & - & & 0.2 & tr & 2.0 & & 0.2 & & 2.1 & 0.2 & 5.6 & tr & tr & & & tr & 3.0 & 2.1 & & & & & 15.3 & \\
\hline
\end{tabular}


Common name

Species

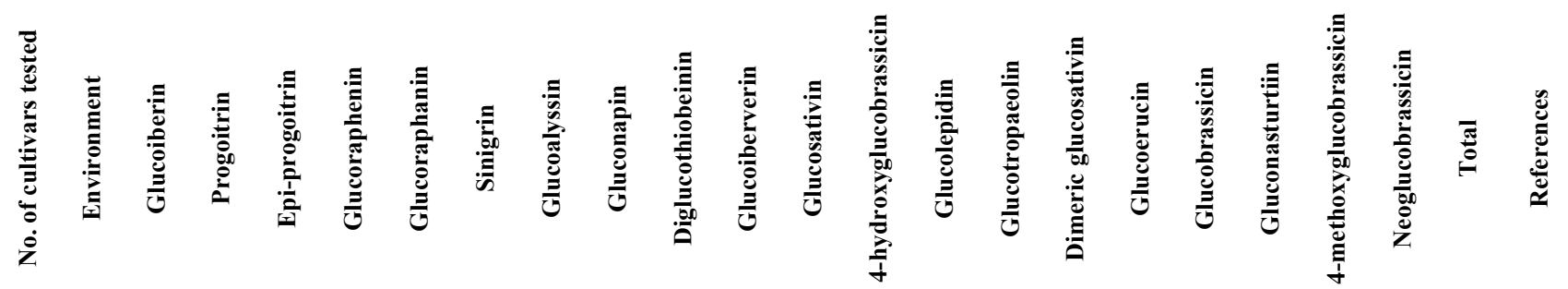

\begin{tabular}{|c|c|c|c|c|c|c|c|c|c|c|c|c|c|c|c|c|c|c|c|c|c|c|c|c|c|}
\hline \multirow{4}{*}{ Wild rocket } & & 7 & $\mathrm{CE}$ & & nd & & $<0.1$ & 0.2 & & nd & & nd & $<0.1$ & 2.4 & $<0.1$ & $<0.1$ & $<0.1$ & 4.7 & 0.2 & & & & & 7.7 & 62 \\
\hline & Diplotaxis tenuifolia & 1 & $\mathrm{CE}$ & & nd & & nd & 0.4 & & nd & & 1.1 & 0.9 & 3.6 & nd & nd & nd & nd & 0.8 & & & & & 6.8 & 63 \\
\hline & & 16 & G & & 0.4 & & nd & 4.6 & & 0.8 & & 3.5 & nd & 2.0 & nd & nd & nd & 5.5 & 2.2 & & & & & 19.0 & 65 \\
\hline & Average & - & - & & 0.1 & & $\operatorname{tr}$ & 1.7 & & 0.3 & & 1.5 & 0.3 & 2.7 & $\operatorname{tr}$ & $\operatorname{tr}$ & tr & 3.4 & 1.1 & & & & & 11.2 & \\
\hline \multirow{6}{*}{ Kale } & & 1 & $\mathrm{CE}$ & 2.0 & nd & & & 0.4 & 0.4 & & nd & & & & 0.2 & & & & nd & 2.1 & $<0.1$ & $<0.1$ & 0.2 & 5.3 & 52 \\
\hline & & 153 & $\mathrm{~F}$ & 3.2 & 0.3 & & & 0.1 & 3.9 & & nd & & & & nd & & & & nd & 2.9 & $<0.1$ & nd & 0.3 & 10.7 & 37 \\
\hline & Brassica oleracea var. acephala & & & & & & & & & & & & & & & & & & & & & & & & \\
\hline & & 5 & $\mathrm{~F}$ & 1.3 & 3.1 & & & 0.6 & 0.6 & & 0.1 & & & & nd & & & & $<0.1$ & 2.9 & 0.4 & nd & nd & 15.1 & 18 \\
\hline & & 2 & G & 1.1 & $<0.1$ & & & 0.1 & 0.4 & & nd & & & & 0.1 & & & & nd & 1.8 & nd & 0.1 & 0.3 & 3.9 & 19 \\
\hline & Average & - & - & 1.9 & 0.9 & & & 0.3 & 1.3 & & $<0.1$ & & & & 0.1 & & & & $\operatorname{tr}$ & 2.4 & 0.1 & $<0.1$ & 0.2 & 8.8 & \\
\hline \multirow{8}{*}{ Cabbage } & & 1 & $\mathrm{CE}$ & nd & nd & nd & & 0.1 & 1.1 & nd & 0.1 & & nd & & nd & & & & & 0.1 & $<0.1$ & nd & nd & 1.8 & 36 \\
\hline & & 26 & $\mathrm{~F}$ & 2.7 & 0.3 & 0.3 & & $<0.1$ & 1.0 & $<0.1$ & $<0.1$ & & $<0.1$ & & $<0.1$ & & & & & 2.5 & nd & nd & 0.2 & 7.2 & 37 \\
\hline & Brassica oleracea var. capitata & 6 & $\mathrm{~F}$ & 0.2 & 0.6 & nd & & 0.2 & 0.6 & nd & 0.2 & & $<0.1$ & & nd & & & & & 0.8 & nd & 0.1 & $<0.1$ & 2.5 & 1 \\
\hline & & 2 & G & 1.6 & 0.3 & nd & & 1.1 & 1.7 & nd & 0.2 & & nd & & 0.1 & & & & & 2.6 & nd & 0.3 & 0.3 & 8.8 & 25 \\
\hline & & 1 & $?$ & 2.9 & 0.1 & nd & & 0.1 & 4.1 & nd & nd & & nd & & nd & & & & & 2.7 & nd & 0.5 & nd & 10.3 & \multirow{3}{*}{31,32} \\
\hline & Brassica oleracea var. capitata f. Savoy & 1 & $?$ & 1.7 & 0.1 & nd & & 0.1 & 1.7 & 0.2 & 0.2 & & nd & & 0.2 & & & & & 1.0 & nd & 0.7 & $<0.1$ & 5.8 & \\
\hline & Brassica oleracea var. capitata f. Oxheart & 1 & $?$ & 0.3 & 0.1 & nd & & 0.1 & $<0.1$ & 0.4 & nd & & nd & & $<0.1$ & & & & & 0.4 & nd & $<0.1$ & nd & 1.4 & \\
\hline & Average & - & - & 1.3 & 0.2 & $<0.1$ & & 0.2 & 1.5 & 0.1 & 0.1 & & tr & & $<0.1$ & & & & & 1.4 & tr & 0.2 & 0.1 & 4.1 & \\
\hline
\end{tabular}




\begin{tabular}{|c|c|c|c|c|c|c|c|c|c|c|c|c|c|c|c|c|c|c|c|}
\hline Common name & Species & 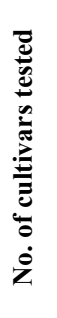 & 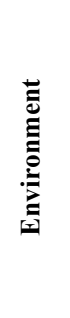 & 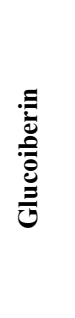 & 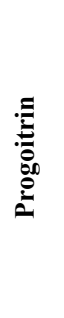 & 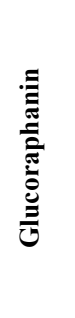 & 漓 & 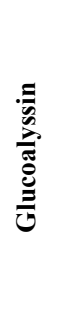 & 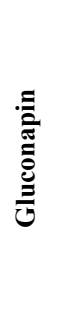 & 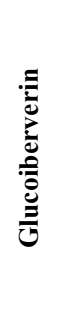 & 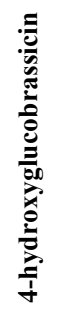 & 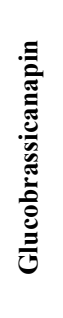 & 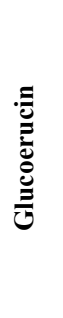 & 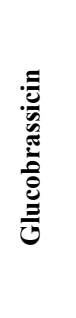 & 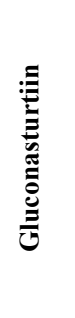 & 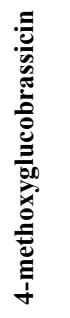 & 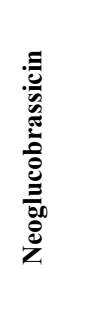 & $\stackrel{\bar{\pi}}{\stackrel{\pi}{\theta}}$ & 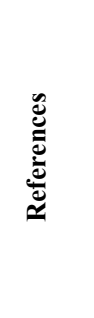 \\
\hline \multirow{6}{*}{ Red cabbage } & & 4 & $\mathrm{~F}$ & 0.1 & 0.6 & 0.3 & 0.2 & nd & 0.3 & $<0.1$ & nd & & nd & 1.7 & $<0.1$ & 0.1 & 0.2 & 3.4 & 1 \\
\hline & & 1 & $\mathrm{G} / \mathrm{F}$ & 1.5 & 3.6 & 0.6 & 1.6 & nd & 1.4 & nd & 0.3 & & 0.3 & 1.2 & 0.1 & 1.9 & nd & 18.4 & 39 \\
\hline & Brassica oleracea var. capitata f. rubra & 1 & ? & 0.6 & 0.5 & $<0.1$ & 1.1 & 0.1 & 0.2 & nd & $<0.1$ & & nd & 1.5 & nd & 0.1 & nd & 4.1 & 31,32 \\
\hline & & 1 & $?$ & 0.4 & 0.7 & 1.3 & 0.6 & nd & 1.3 & nd & 0.1 & & nd & 0.2 & nd & 0.1 & nd & 4.7 & 40 \\
\hline & & $1^{*}$ & $?$ & nd & nd & 1.1 & 1.3 & nd & nd & nd & 0.2 & & nd & 0.3 & nd & 0.3 & nd & 3.0 & 41 \\
\hline & Average & - & - & 0.5 & 1.1 & 0.7 & 1.0 & $<0.1$ & 0.6 & $\operatorname{tr}$ & 0.1 & & 0.1 & 1.0 & $<0.1$ & 0.5 & $<0.1$ & 6.7 & \\
\hline \multirow{3}{*}{ White cabbage } & & $?$ & $?$ & 1.2 & 0.3 & nd & 1.1 & nd & & & & & & nd & & nd & nd & 2.6 & 38 \\
\hline & Brassica oleracea var. capitata f. alba & 1 & $?$ & 2.7 & 0.1 & 0.1 & 1.7 & $<0.1$ & & & & & & 1.4 & & 0.2 & $<0.1$ & 6.1 & 31,32 \\
\hline & Average & - & - & 2.0 & 0.2 & 0.1 & 1.4 & $\operatorname{tr}$ & & & & & & 0.7 & & 0.1 & $\operatorname{tr}$ & 4.4 & \\
\hline \multirow[t]{2}{*}{ Collards } & Brassica oleracea var. sabellica & 5 & $\mathrm{~F}$ & 1.0 & 2.9 & 0.3 & 6.5 & & 0.7 & & & & & 4.6 & 0.1 & & & 18.2 & 18,19 \\
\hline & & 1 & $\mathrm{CE}$ & & & nd & 3.9 & & 0.2 & & & & & $<0.1$ & 0.1 & & & 4.3 & 36 \\
\hline \multirow[t]{2}{*}{ Mustard greens } & Brassica juncea & 2 & $\mathrm{~F}$ & & & $<0.1$ & 29.3 & & 0.2 & & & & & 0.3 & 0.3 & & & 47.4 & 18,19 \\
\hline & Average & - & 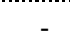 & & & $\operatorname{tr}$ & 16.6 & & 0.2 & & & & & 0.2 & 0.2 & & & 25.9 & \\
\hline Leaf rape & Brassica napus var. pabularia & 36 & G & & 2.2 & & & 0.4 & 1.1 & & & 3.2 & & 0.4 & & & & 7.9 & 53 \\
\hline
\end{tabular}

* = Cultivars were purchased from multiple supermarkets but treated as one sample 


\begin{tabular}{|c|c|c|c|c|c|c|c|c|c|c|c|c|c|c|c|c|c|c|c|c|c|c|c|c|c|c|}
\hline Common name & Species & 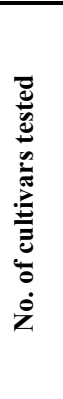 & 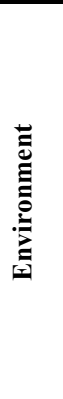 & 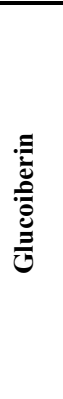 & 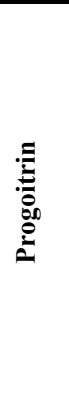 & 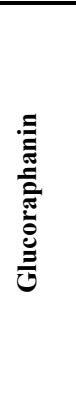 & 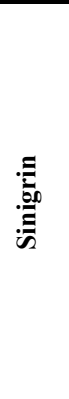 & 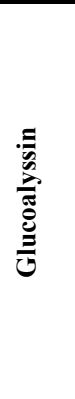 & 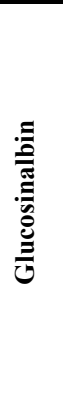 & 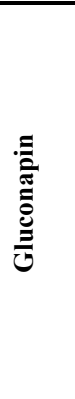 & 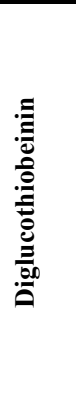 & 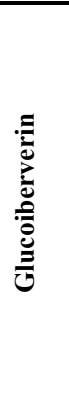 & 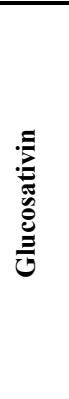 & 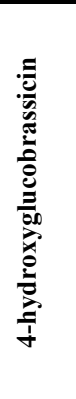 & 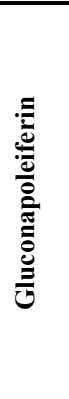 & 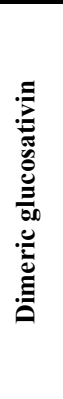 & 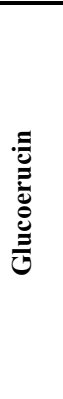 & 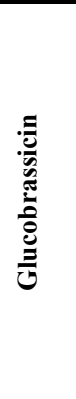 & 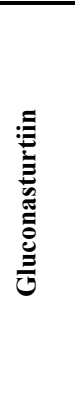 & 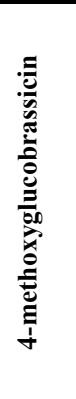 & 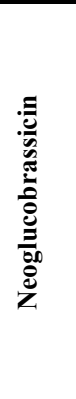 & 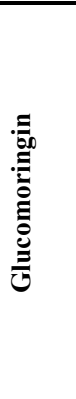 & 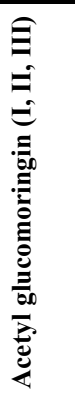 & 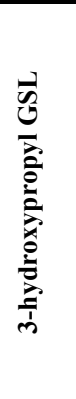 & $\stackrel{\bar{\pi}}{\theta}$ & 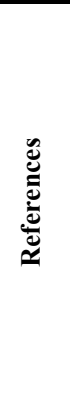 \\
\hline \multirow{3}{*}{ Watercress } & \multirow{2}{*}{ Nasturtium officinale } & 1 & $\mathrm{CE}$ & & & & & & & & & & & nd & & & & 0.2 & 6.6 & nd & & & & & 7.1 & 36 \\
\hline & & 1 & $\mathrm{H}^{\S}$ & & & & & & & & & & & 0.2 & & & & 0.5 & 1.8 & 0.3 & & & & & 2.8 & 71 \\
\hline & Average & 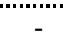 & - - & & & & & & & & & & & 0.1 & & & & 0.4 & 4.2 & 0.2 & & & & & 5.0 & \\
\hline Chinese kale & Brassica oleracea var. alboglabra & 1 & $\mathrm{~F}$ & 0.1 & 1.9 & 4.0 & 0.1 & & & 7.6 & & $<0.1$ & & 0.2 & 0.1 & & 0.1 & 0.6 & & 0.1 & 0.2 & & & & 14.9 & 21 \\
\hline Turnip rape & Brassica napus & 1 & $\mathrm{CE}$ & & & & $<0.1$ & & & 4.8 & & & & & & & & 0.1 & 0.7 & & & & & & 5.6 & 36 \\
\hline Dogmustard & Erucastrum spp. & 1 & $\mathrm{G}$ & & $<0.1$ & 1.9 & & 0.9 & & & $<0.1$ & & $<0.1$ & & & 0.2 & 0.6 & & & & & & & & 3.6 & \\
\hline White mustard & Sinapis alba & 1 & G & & & & 2.0 & & 27.1 & & & & & & & & & & & & & & & & 29.1 & 24 \\
\hline \multirow{5}{*}{ Moringa } & \multirow{4}{*}{ Moringa oleifera } & 6 & $\mathrm{~F}^{\vee}$ & & & & & & & & & & & & & & & & & & & 50.2 & 9.3 & & 59.5 & 60 \\
\hline & & 30 & $\mathrm{~F}$ & & & & & & & & & & & & & & & & & & & 12.0 & 12.0 & & 24.0 & 57 \\
\hline & & 1 & $\mathrm{G} / \mathrm{F}$ & & & & & & & & & & & & & & & & & & & 17.1 & 11.8 & & 28.9 & 59 \\
\hline & & 6 & G & & & & & & & & & & & & & & & & & & & 48.5 & 34.2 & & 82.7 & $58^{\wedge}$ \\
\hline & Average & - & - & & & & & & & & & & & & & & & & & & & 29.3 & 14.1 & & 43.4 & \\
\hline Spider plant & Cleome gynandra & 6 & $\mathrm{~F}$ & & & & & & & & & & & & & & & & & & & & & 3.1 & 3.1 & 69 \\
\hline \multirow{3}{*}{ Ethiopian mustard } & Brassica carinata & 2 & $\mathrm{CE}$ & & $<0.1$ & & 6.9 & $<0.1$ & & $<0.1$ & & & & $<0.1$ & & & & 0.1 & nd & $<0.1$ & $<0.1$ & & & & 7.1 & 48 \\
\hline & & 1 & G & & nd & & 1.3 & nd & & 0.1 & & & & nd & & & & 0.2 & $<0.1$ & $<0.1$ & $<0.1$ & & & & 1.7 & 49 \\
\hline & Average & - & - & & $\operatorname{tr}$ & & 4.1 & tr & & 0.1 & & & & tr & & & & 0.2 & tr & $<0.1$ & $<0.1$ & & & & 4.4 & \\
\hline \multicolumn{27}{|l|}{ Sprouts } \\
\hline Broccoli & Average & - & - & 2.0 & tr & 13.0 & & tr & & tr & & & & 2.75 & & & 2.1 & 3.5 & tr & 3.2 & 2.4 & & & & 28.9 & \\
\hline
\end{tabular}

$\$=$ cultivars were grown commercially in outdoor water beds; $\wedge=$ concentrations determined from reported $\%$ of total; $\vee=$ grown in various geographical locations. 


\begin{tabular}{|c|c|c|c|c|c|c|c|c|c|c|c|c|c|c|c|c|c|c|c|c|c|c|c|}
\hline Common name & Species & 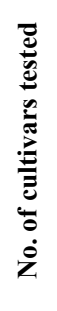 & 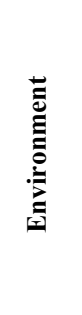 & 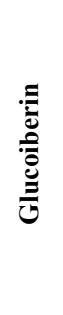 & 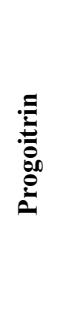 & 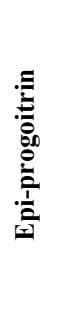 & 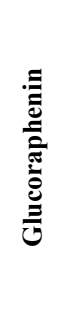 & 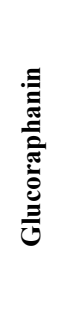 & 咅 & 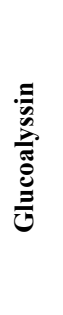 & 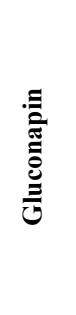 & 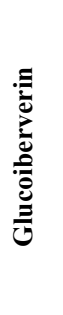 & 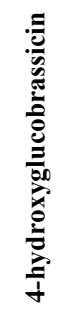 & 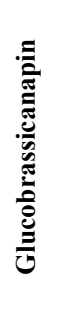 & 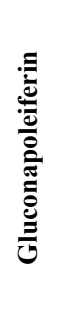 & 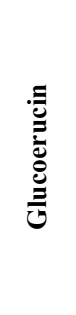 & 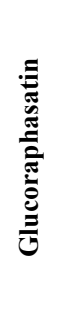 & 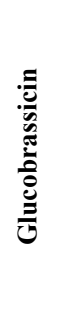 & 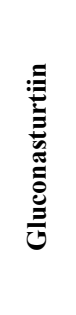 & 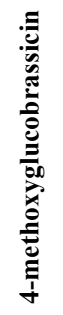 & 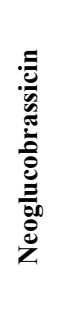 & 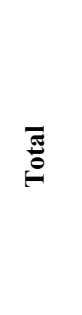 & 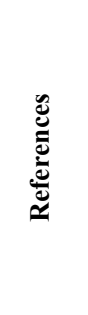 \\
\hline Turnip & Brassica rapa var. rapa & 1 & $\mathrm{CE}$ & & 4.2 & & & & & 0.1 & 0.8 & & 2.4 & $\operatorname{tr}$ & $\operatorname{tr}$ & & & 2.3 & & 2.2 & 2.4 & 15.0 & \multirow{4}{*}{11} \\
\hline Rutabaga & Brassica napus var. rapifera & 1 & $\mathrm{CE}$ & & 18.5 & & & & & & 1.6 & & 1.7 & $\operatorname{tr}$ & $\operatorname{tr}$ & & & 3.0 & & 3.8 & 3.4 & 31.9 & \\
\hline China rose radish & Raphanus sativus & 1 & $\mathrm{CE}$ & & & & 3.3 & & & & & & 1.5 & & & 0.2 & 41.1 & & & 2.7 & & 48.8 & \\
\hline Radish & & 1 & $\mathrm{CE}$ & & & & 16.7 & & & & & & 2.7 & & & & 17.2 & & & $\operatorname{tr}$ & & 36.6 & \\
\hline \multirow{2}{*}{ Chinese kale } & Brassica oleracea var. alboglabra & 1 & H & 1.0 & $\begin{array}{l}28.7 \\
119\end{array}$ & & & $\begin{array}{l}1.7 \\
\text { nd }\end{array}$ & $\begin{array}{l}16.7 \\
\text { nd }\end{array}$ & & $\begin{array}{r}45.9 \\
15.9\end{array}$ & & $\begin{array}{l}0.6 \\
\text { nd }\end{array}$ & & $\begin{array}{l}0.4 \\
\text { nd }\end{array}$ & $\begin{array}{l}0.5 \\
\text { nd }\end{array}$ & & $\begin{array}{l}0.9 \\
0.6\end{array}$ & & $\begin{array}{l}1.8 \\
3.0\end{array}$ & $\begin{array}{l}0.2 \\
\text { nd }\end{array}$ & $\begin{array}{l}98.2 \\
32.8\end{array}$ & $\begin{array}{l}46 \\
47\end{array}$ \\
\hline & Average & -...... & - & 1.1 & 20.3 & & & 0.9 & 8.4 & & $3 \ldots \ldots$ & & 0.3 & & 0.2 & 0.3 & & 0.8 & & 2.4 & 0.1 & 65.5 & ....... \\
\hline \multicolumn{24}{|l|}{ Florets/Buds } \\
\hline \multirow{7}{*}{ Broccoli } & \multirow{7}{*}{ Brassica oleracea var. italica } & 1 & $\mathrm{CE} / \mathrm{F}$ & 1.7 & nd & nd & & 17.4 & nd & nd & nd & nd & 1.8 & nd & nd & nd & & 4.0 & nd & 0.8 & 1.2 & 26.9 & 16 \\
\hline & & 10 & $\mathrm{~F}$ & nd & 0.4 & nd & & 4.0 & $<0.1$ & nd & nd & nd & nd & $\mathrm{nd}$ & nd & nd & & nd & nd & nd & nd & 6.4 & 17 \\
\hline & & 6 & $\mathrm{~F}$ & 0.3 & 0.1 & nd & & 2.3 & $<0.1$ & nd & $<0.1$ & nd & nd & nd & nd & 0.1 & & 2.3 & $<0.1$ & nd & nd & 7.3 & 18,19 \\
\hline & & 6 & $\mathrm{~F}$ & 0.4 & nd & nd & & 2.2 & nd & nd & nd & nd & 0.1 & nd & nd & nd & & 1.4 & nd & 0.6 & 0.2 & 4.9 & 20 \\
\hline & & 4 & $\mathrm{~F}$ & 0.2 & 0.3 & nd & & 1.8 & $<0.1$ & nd & $<0.1$ & nd & $<0.1$ & nd & 0.1 & $<0.1$ & & 0.9 & nd & 0.1 & 0.3 & 3.9 & 21 \\
\hline & & 1 & $\mathrm{~F}$ & 0.3 & nd & nd & & 1.7 & $\mathrm{nd}$ & nd & $\mathrm{nd}$ & nd & 0.1 & $\mathrm{nd}$ & nd & $\mathrm{nd}$ & & 0.6 & $\mathrm{nd}$ & 0.1 & 0.3 & 3.1 & 22 \\
\hline & & 1 & $\mathrm{~F}$ & 0.7 & nd & nd & & 4.6 & nd & nd & nd & nd & 0.1 & $\mathrm{nd}$ & nd & nd & & 1.7 & nd & 3.8 & 0.2 & 11.1 & 23 \\
\hline
\end{tabular}




\begin{tabular}{|c|c|c|c|c|c|c|c|c|c|c|c|c|c|c|c|c|c|c|c|c|c|c|}
\hline Common name & Species & 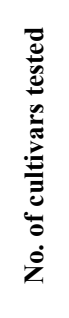 & 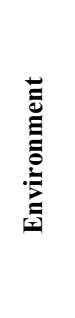 & 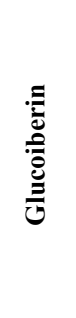 & 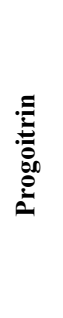 & 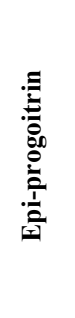 & 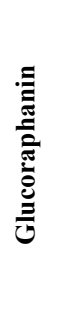 & 离 & 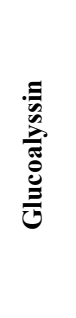 & 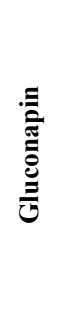 & 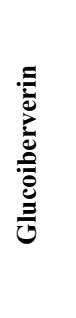 & 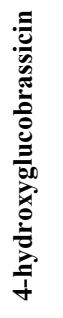 & 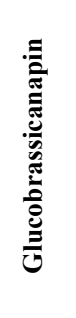 & 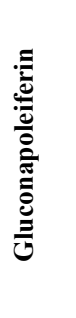 & 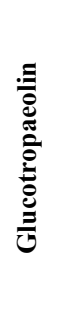 & 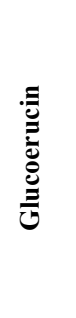 & 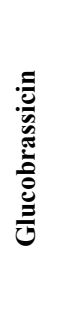 & 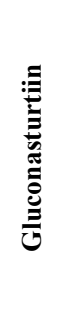 & 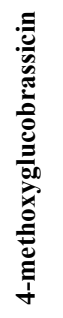 & 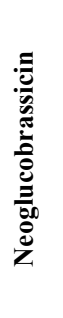 & $\stackrel{\bar{\pi}}{\stackrel{5}{6}}$ & 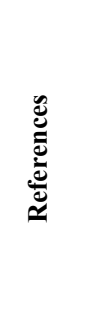 \\
\hline \multirow{12}{*}{$\begin{array}{l}\text { Broccoli } \\
\text { (continued) }\end{array}$} & \multirow{11}{*}{ Brassica oleracea var. italica } & 1 & $\mathrm{~F}$ & nd & nd & nd & 0.9 & nd & nd & nd & nd & nd & nd & nd & & nd & nd & $<0.1$ & nd & nd & 1.0 & 24 \\
\hline & & 2 & G & nd & nd & nd & 4.6 & nd & nd & nd & nd & 0.2 & nd & nd & & nd & 2.6 & nd & 0.3 & 1.9 & 9.3 & 25 \\
\hline & & 148 & G & 0.1 & 0.9 & 0.6 & 1.4 & $<0.1$ & $<0.1$ & 0.1 & nd & 0.1 & nd & nd & & 0.1 & 2.0 & nd & 0.3 & 0.7 & 5.8 & 87 \\
\hline & & 50 & $\mathrm{G} / \mathrm{F}$ & $<0.1$ & 0.1 & nd & 2.8 & $<0.1$ & 0.1 & 0.4 & nd & 0.1 & 0.1 & 0.3 & & nd & 0.4 & 0.2 & 0.2 & 0.1 & 5.1 & 26,27 \\
\hline & & - & M & 1.6 & 3.2 & $<0.1$ & 7.7 & $<0.1$ & 1.2 & 0.2 & $<0.1$ & 0.1 & $<0.1$ & 0.2 & & $<0.1$ & 6.9 & 0.1 & 0.4 & 4.0 & 25.6 & $28^{+}$ \\
\hline & & 2 & $?$ & nd & nd & nd & 8.3 & nd & nd & nd & nd & nd & nd & nd & & nd & nd & nd & nd & nd & 8.3 & 29 \\
\hline & & - & $?$ & nd & nd & nd & 1.9 & nd & nd & nd & nd & $\mathrm{nd}$ & nd & nd & & nd & nd & nd & nd & nd & 2.4 & 30 \\
\hline & & 1 & $?$ & 0.2 & 2.3 & nd & 0.1 & nd & 2.3 & 0.2 & nd & nd & nd & nd & & nd & 0.8 & nd & 0.1 & 0.4 & 6.6 & 31,32 \\
\hline & & 1 & ? & 1.3 & nd & nd & 3.2 & nd & nd & nd & nd & nd & nd & nd & & nd & 0.4 & nd & 0.1 & 0.6 & 5.6 & 33 \\
\hline & & 1 & $?$ & 0.2 & nd & nd & 0.9 & nd & nd & nd & nd & 0.1 & nd & nd & & nd & 0.7 & nd & 0.4 & 0.2 & 2.5 & 34 \\
\hline & & 1 & $?$ & 0.3 & nd & nd & 2.8 & nd & nd & nd & nd & 0.1 & nd & nd & & nd & 2.3 & nd & 0.3 & 0.9 & 6.9 & 14 \\
\hline & Average & - & - & 0.4 & 0.4 & $<0.1$ & 3.8 & 0.4 & 0.2 & $<0.1$ & $\operatorname{tr}$ & 0.1 & $<0.1$ & $<0.1$ & & $<0.1$ & 1.5 & $<0.1$ & 0.4 & 0.5 & 7.9 & \\
\hline \multirow{6}{*}{ Brussels sprouts } & \multirow{5}{*}{ Brassica oleracea var. gemmifera } & 6 & $\mathrm{~F}$ & 0.4 & 0.5 & & 0.5 & 0.5 & nd & 0.3 & $<0.1$ & nd & & & nd & $<0.1$ & 15.8 & $<0.1$ & nd & nd & 22.4 & 18,19 \\
\hline & & 1 & $\mathrm{~F}$ & 0.1 & 2.1 & & nd & 10.5 & nd & 0.9 & nd & nd & & & 0.4 & nd & 2.6 & 0.2 & 0.7 & 0.1 & 17.6 & 35 \\
\hline & & 2 & G & 1.4 & 0.8 & & 0.6 & 0.9 & nd & 0.3 & nd & 0.2 & & & nd & nd & 4.4 & nd & 0.4 & 0.2 & 10.3 & 25 \\
\hline & & 1 & ? & 1.2 & 3.0 & & 0.1 & 3.3 & 0.8 & 2.8 & nd & 0.5 & & & nd & nd & 1.8 & 0.1 & 0.6 & nd & 13.9 & 31,32 \\
\hline & & 1 & $?$ & 0.9 & nd & & 0.2 & nd & nd & nd & nd & 0.1 & & & nd & nd & 0.9 & nd & nd & 0.1 & 2.2 & 34 \\
\hline & Average & - & - & 0.8 & 1.3 & & 0.3 & 3.0 & 0.2 & 0.9 & tr & 0.2 & & & 0.1 & tr & 5.1 & 0.1 & 0.3 & 0.1 & 13.3 & \\
\hline
\end{tabular}

\footnotetext{
$+=$ Median values taken from range data
} 


\begin{tabular}{|c|c|c|c|c|c|c|c|c|c|c|c|c|c|c|c|c|c|c|c|c|c|c|c|}
\hline Common name & Species & 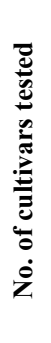 & 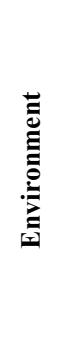 & 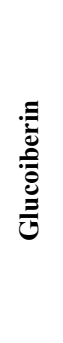 & 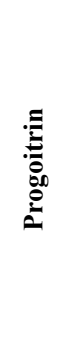 & 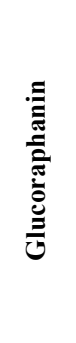 & 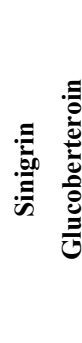 & 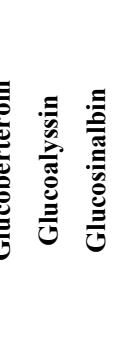 & 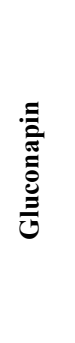 & 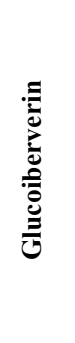 & 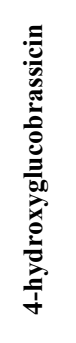 & 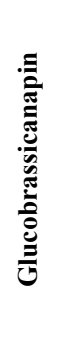 & 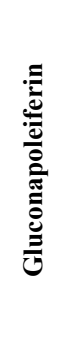 & 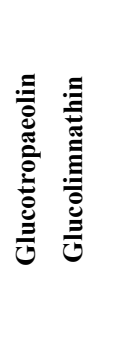 & 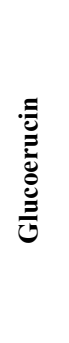 & 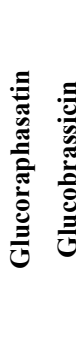 & 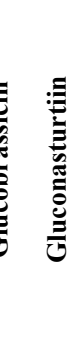 & 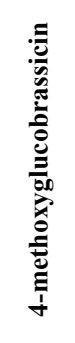 & 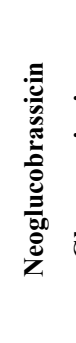 & 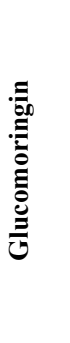 & 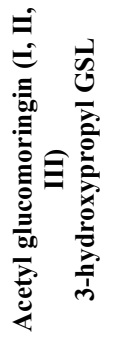 & हैं & 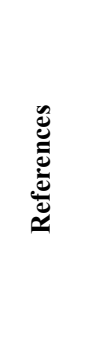 \\
\hline \multirow{8}{*}{ Cauliflower } & \multirow{7}{*}{ Brassica oleracea var. botrytis } & 5 & $\mathrm{~F}$ & 0.5 & nd & $<0.1$ & 0.3 & & $<0.1$ & 0.2 & nd & & nd & & $<0.1$ & 2.5 & $.5<0.1$ & nd & nd & & & 4.0 & 18,19 \\
\hline & & 4 & $\mathrm{~F}$ & 0.9 & 0.1 & 0.4 & 0.1 & & $<0.1$ & 0.1 & $<0.1$ & & $<0.1$ & & $<0.1$ & 0. & $9 \mathrm{nd}$ & 0.1 & 0.1 & & & 2.9 & 21 \\
\hline & & 1 & $\mathrm{~F}$ & 0.7 & 0.1 & 0.1 & 0.7 & & nd & nd & nd & & nd & & nd & 0. & $9 \mathrm{nd}$ & $<0.1$ & $<0.1$ & & & 2.5 & 22 \\
\hline & & 2 & G & 0.6 & 0.1 & $<0.1$ & 0.8 & & $<0.1$ & nd & 0.2 & & nd & & nd & 2.2 & $3 \mathrm{nd}$ & 0.2 & 1.5 & & & 5.8 & 25 \\
\hline & & 5 & $\mathrm{G} / \mathrm{F}$ & 1.3 & 2.5 & 0.9 & 0.6 & & nd & nd & 0.7 & & nd & & 0.1 & 4. & $1 \mathrm{nd}$ & 0.7 & 0.5 & & & 11.4 & 42 \\
\hline & & 1 & $?$ & 0.1 & nd & 0.1 & 0.1 & & nd & nd & $<0.1$ & & nd & & nd & 0. & $3 \mathrm{nd}$ & 0.1 & $<0.1$ & & & 0.7 & 31,32 \\
\hline & & 1 & $?$ & 0.4 & nd & $<0.1$ & nd & & nd & nd & $<0.1$ & & nd & & nd & 0. & $7 \mathrm{nd}$ & 0.2 & 0.1 & & & 1.5 & 34 \\
\hline & Average & - & - & 0.6 & 0.4 & 0.2 & 0.4 & & $\operatorname{tr}$ & $<0.1$ & 0.1 & & tr & & $<0.1$ & 1. & $.7 \operatorname{tr}$ & 0.2 & 0.3 & & & 4.1 & \\
\hline \multicolumn{24}{|l|}{ Stem } \\
\hline \multirow{3}{*}{ Kohlrabi } & Brassica oleracea var. gongylodes & 1 & $\mathrm{~F}$ & 0.1 & $<0.1$ & 0.2 & & nd & & 0.4 & nd & & & & 1.3 & 1. & $\begin{array}{ll}1 & 0.1\end{array}$ & nd & nd & & & 3.4 & 18,19 \\
\hline & & 1 & $?$ & 0.1 & nd & $<0.1$ & & 0.1 & & nd & $<0.1$ & & & & nd & 0. & $5 \mathrm{nd}$ & $<0.1$ & 0.2 & & & 1.0 & 31,32 \\
\hline & Average & -... & - & 0.1 & tr & $\begin{array}{c}0.1 \\
\ldots y .\end{array}$ & & 0.1 & & 0.2 & $\operatorname{tr}$ & & & & 0.7 & 0.8 & 80.1 & tr & 0.1 & & & 2.2 & \\
\hline Moringa & Moringa oleifera & 1 & F & & & & & & & & & & & & & & & & & 16.3 & 4.8 & 21.1 & 60 \\
\hline Spider plant & Cleome gynandra & 8 & $\mathrm{~F}$ & & & & & & & & & & & & & & & & & & 7.6 & 7.6 & 69 \\
\hline Ethiopian mustard & Brassica carinata & 1 & G & & & & 2.8 & & 0.4 & & 0.1 & & & & & 0.2 & $2 \quad 2.3$ & 0.1 & 0.1 & & & 6.0 & 49 \\
\hline \multicolumn{24}{|l|}{ Root } \\
\hline \multirow{3}{*}{ Rutabaga } & & 1 & $\mathrm{CE}$ & & 2.8 & nd & & 20.2 & & & 0.1 & $0.1 \quad 0$ & 0.4 & & 0.4 & 0.2 & $2 \mathrm{nd}$ & 0.1 & 0.1 & & & 5.6 & 68 \\
\hline & Brassica oleracea var. rapıfera & 1 & $?$ & & 0.9 & 0.3 & & $\mathrm{~d}$ nd & & & 0.1 & nd 1 & nd & & nd & 0. & $4 \quad 1.2$ & 0.1 & 0.4 & & & 3.5 & 31,32 \\
\hline & Average & - & - & & 1.9 & 0.2 & & 60.1 & & & 0.1 & 0.10 & 0.2 & & 0.2 & 0. & 30.6 & 0.1 & 0.3 & & & 4.6 & \\
\hline Maca & Lepidium mеуепii & 3 & $\mathrm{~F}$ & & & & & $\begin{array}{ll}0.1 & 0.2\end{array}$ & & & & & & $\begin{array}{lll}6.9 & 1.5 \\
\cdots\end{array}$ & & & & & & & & 8.6 & 54 \\
\hline Radish & Raphanus sativus & 1 & $?$ & 0.1 & & 0.1 & & & & & & & & & & 1.90. & 10.1 & 0.2 & & & & 2.8 & 31,32 \\
\hline Moringa & Moringa oleifera & 3 & $\mathrm{~F}^{\vee}$ & & & & & & & & & & & & & & & & & 8.6 & 10.2 & 18.8 & 60 \\
\hline
\end{tabular}


Table 2. Summary of factors that influence glucosinolate composition of Brassicaceae plants during cultivation

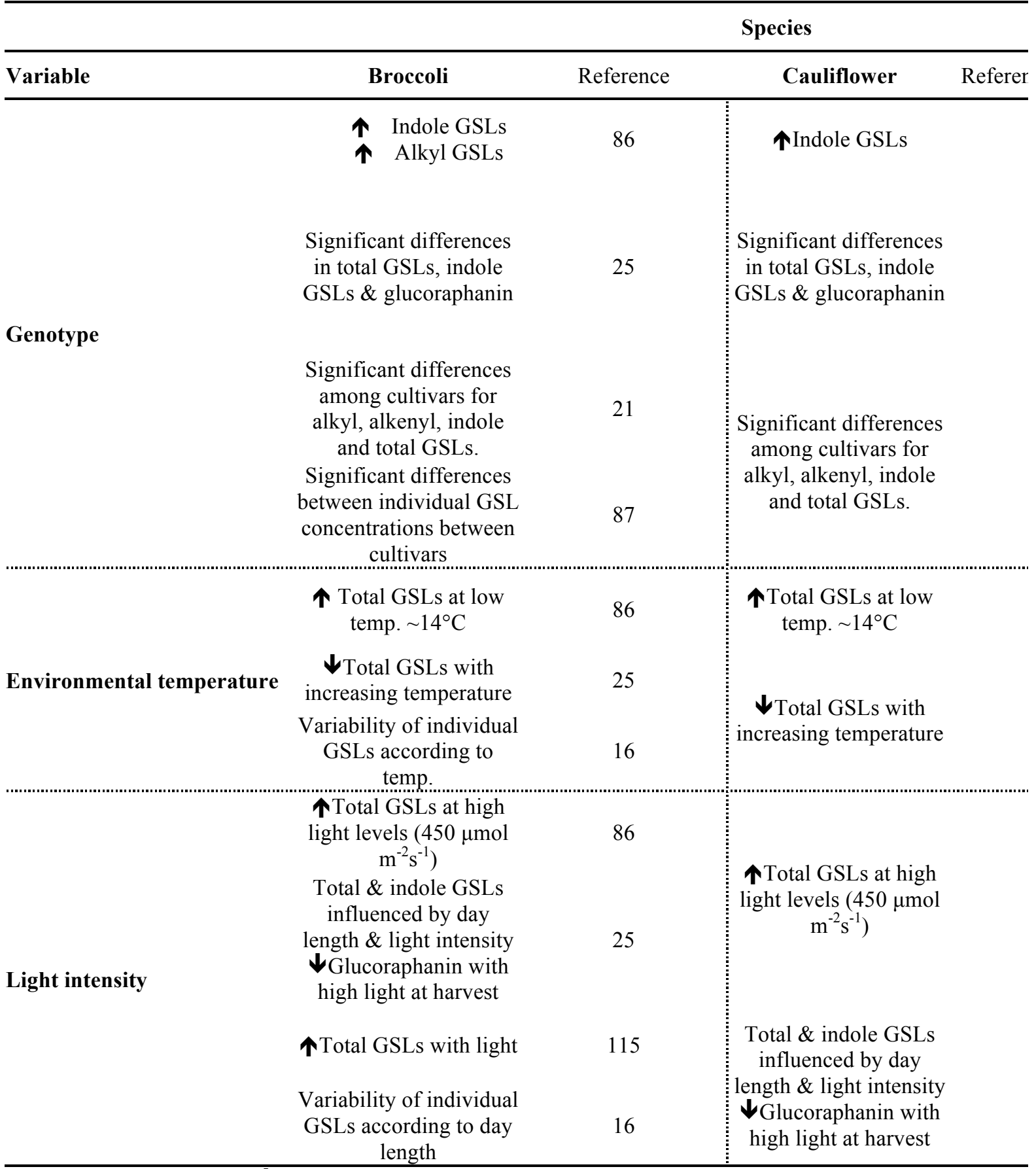

个Increase; $\leftrightarrow \rightarrow$ no-effect; $\downarrow$ decrease 
Table 2. Continued

\begin{tabular}{|c|c|c|c|c|c|c|}
\hline Variable & \multicolumn{6}{|c|}{ Species } \\
\hline \multirow[t]{2}{*}{ Sulfur application } & $\begin{array}{c}\leftrightarrow \rightarrow\left(150 \mathrm{~kg} \mathrm{~S} \mathrm{ha}^{-1}\right) \\
\leftrightarrow \rightarrow \text { Low S }\left(15 \mathrm{~kg} \mathrm{~S}^{-1}\right)\end{array}$ & 115 & - & - & \multirow[t]{2}{*}{$\begin{array}{l}\text { Alkenyl GSLs (30 mg } \\
\text { S per plant) }\end{array}$} & \multirow[t]{2}{*}{86} \\
\hline & $\begin{array}{l}\text { 个Aliphatic \& total } \\
\text { GSLs }\left(>15 \mathrm{mg} \cdot \mathrm{L}^{-1}\right)\end{array}$ & 15 & & & & \\
\hline Nitrogen application & $\begin{array}{c}\text { TTotal GSLs with } \\
\text { reduced N } \\
\text { 个Total GSLs with } \\
\text { reduced N (1g N per } \\
\text { plant) }\end{array}$ & 115 & $\begin{array}{l}\text { 个Total GSLs with } \\
\text { reduced N }\end{array}$ & 86 & $\begin{array}{l}\boldsymbol{\uparrow} \text { Total GSLs with } \\
\text { reduced N }\end{array}$ & 86 \\
\hline Water availability & $\begin{array}{l}\text { 个Total GSLs with } \\
\text { reduced water } \\
\text { 个Total GSLs with } \\
\text { severe drought }\end{array}$ & 86 & $\begin{array}{l}\text { TTotal GSLs with } \\
\text { reduced water }\end{array}$ & 86 & $\begin{array}{l}\text { 个Total GSLs with } \\
\text { reduced water }\end{array}$ & 86 \\
\hline Soil salinity & $\begin{array}{l}\text { 个Total GSLs (40, } \\
80 \mathrm{mM})\end{array}$ & 115 & - & - & - & - \\
\hline
\end{tabular}

个Increase; $\leftrightarrow \rightarrow$ no-effect; $\downarrow$ decrease 
Table 2. Continued

\begin{tabular}{|c|c|c|c|c|c|c|}
\hline \multirow[b]{2}{*}{ Variable } & \multicolumn{6}{|c|}{ Species } \\
\hline & Cabbage & Reference & Brussels sprouts & Reference & Wild rocket & Reference \\
\hline $\begin{array}{l}\text { Environmental } \\
\text { temperature }\end{array}$ & $\begin{array}{l}\boldsymbol{\downarrow} \text { Total GSLs with } \\
\text { increasing temperature } \\
\text { 个Total GSLs at } 32^{\circ} \mathrm{C}\end{array}$ & $\begin{array}{l}25 \\
115\end{array}$ & $\begin{array}{c}\downarrow \text { Total GSLs with } \\
\text { increasing temperature }\end{array}$ & 25 & - & - \\
\hline Selenium application & $\leftrightarrow$ & 127 & - & - & - & - \\
\hline Water availability & $\begin{array}{c}\boldsymbol{\uparrow} \text { Total GSLs with } \\
\text { severe drought } \\
\boldsymbol{\downarrow} \text { Total GSLs under } \\
\text { mild and severe drought }\end{array}$ & 115 & $\begin{array}{c}\leftarrow \rightarrow \text { No effect under } \\
\text { mild drought }\end{array}$ & 25 & - & - \\
\hline Developmental stage & $\begin{array}{l}\text { TGlucoraphanin } \\
\text { between transplanting } \\
\text { \& harvest }\end{array}$ & 25 & $\begin{array}{c}\text { 个Glucoraphanin } \\
\text { between transplanting } \\
\& \text { harvest }\end{array}$ & 25 & - & - \\
\hline
\end{tabular}

个Increase; $\bullet \rightarrow$ no-effect; $\downarrow$ decrease 
Table 2. Continued

\begin{tabular}{|c|c|c|c|c|c|c|}
\hline \multirow[b]{2}{*}{ Variable } & \multicolumn{6}{|c|}{ Species } \\
\hline & Ezo-wasabi & Reference & Salad rocket & Reference & Kale & Reference \\
\hline Genotype & - & - & $\begin{array}{l}\text { Significant differences } \\
\text { between genotypes for } \\
\text { aliphatic and total GSLs }\end{array}$ & 62 & $\begin{array}{l}\text { Significant differences } \\
\text { in total GSLs, indole } \\
\text { GSLs \& glucoraphanin }\end{array}$ & 25 \\
\hline $\begin{array}{l}\text { Environmental } \\
\text { temperature }\end{array}$ & - & - & - & - & $\begin{array}{l}\downarrow_{\text {Total GSLs with }} \\
\text { increasing temperature } \\
\boldsymbol{}_{\text {Total GSLs at cold }} \\
\text { temperatures }\left(9-15^{\circ} \mathrm{C}\right)\end{array}$ & $\begin{array}{l}25 \\
52\end{array}$ \\
\hline Light intensity & $\begin{array}{l}\text { 个Total GSLs; red+blue } \\
\text { light } \\
\text { 个Indolic:aliphatic GSL } \\
\text { ratio; red or green light } \\
\text { 个Aliphatic, } \downarrow \text { indolic } \\
\text { GSLs; blue light }\end{array}$ & 50 & $\leftrightarrow$ & 63 & $\begin{array}{l}\text { Total \& indole GSLs } \\
\text { influenced by day } \\
\text { length \& light intensity } \\
\downarrow \text { Glucoraphanin with } \\
\text { high light at harvest }\end{array}$ & 25 \\
\hline Developmental stage & - & - & - & - & $\begin{array}{c}\text { 个Glucoraphanin } \\
\text { between transplanting } \\
\& \text { harvest }\end{array}$ & 25 \\
\hline Variable & Turnip & Reference & Ethiopian mustard & Reference & Thale cress & Reference \\
\hline Light intensity & - & - & - & - & $\begin{array}{c}\text { Total GSLs with light } \\
\boldsymbol{\downarrow} \text { Total GSLs in the } \\
\text { dark }\end{array}$ & 115 \\
\hline Sulfur application & $\begin{array}{c}\text { 个Total GSLs (60 kg S } \\
\left.\mathrm{ha}^{-1}\right)\end{array}$ & 115 & - & - & - & - \\
\hline Potassium application & $\begin{array}{c}\downarrow \text { Total GSLs with K } \\
\text { deficiency }\end{array}$ & - & - & - & $\begin{array}{c}\text { 个Total GSLs with K } \\
\text { deficiency }\end{array}$ & 115 \\
\hline Water availability & $\begin{array}{l}\text { 个Total GSLs with mild } \\
\text { drought }\end{array}$ & 115 & $\begin{array}{l}\boldsymbol{\leftarrow} \rightarrow \text { No effect under } \\
\text { mild drought } \\
\uparrow \text { Total GSLs with } \\
\text { severe drought }\end{array}$ & 86,115 & $\begin{array}{l}\boldsymbol{\downarrow} \text { Total GSLs under } \\
\text { mild and severe drought }\end{array}$ & 115 \\
\hline
\end{tabular}

Increase; $\leftrightarrow$ no-effect; $\downarrow$ decrease 
Table 2. Continued.

\begin{tabular}{|c|c|c|c|c|c|c|}
\hline & & & Species & & & \\
\hline Variable & Swede & Reference & Chinese cabbage & Reference & Rapeseed & Reference \\
\hline Genotype & - & - & $\begin{array}{c}\text { Significant differences } \\
\text { between genotypes for } \\
\text { glucobrassicin and } \\
\text { gluconasturtiin } \\
\text { Total and indolic } \\
\text { glucosinolates vary } \\
\text { between genotypes }\end{array}$ & 44 & - & - \\
\hline $\begin{array}{l}\text { Environmental } \\
\text { temperature }\end{array}$ & $\begin{array}{c}\text { 个Progoitrin \& } \\
\text { glucoberteroin at } 21^{\circ} \mathrm{C}\end{array}$ & 68 & $\begin{array}{c}\boldsymbol{\uparrow} \text { Total GSLs between } \\
21-34^{\circ} \mathrm{C} \\
\boldsymbol{\Downarrow}^{\text {Total GSLs between }} \\
15-27^{\circ} \mathrm{C}\end{array}$ & 115 & - & - \\
\hline Water availability & - & - & - & - & $\begin{array}{l}\text { 个Total GSLs with } \\
\text { severe drought } \\
\leftrightarrow \rightarrow \text { No effect under } \\
\text { mild drought }\end{array}$ & 115 \\
\hline Soil salinity & - & - & $\begin{array}{l}\text { 个Total GSLs (40, } \\
80 \mathrm{mM})\end{array}$ & 115 & - & - \\
\hline Variable & White mustard & Reference & Chinese kale & Reference & & \\
\hline Genotype & - & - & $\begin{array}{l}\text { Significant differences } \\
\text { among cultivars for } \\
\text { alkyl, alkenyl, indole } \\
\text { and total GSLs. }\end{array}$ & 21 & & \\
\hline Light intensity & - & - & $\begin{array}{c}\begin{array}{c}\text { Gluconapin under } \\
\text { blue light }\end{array} \\
\text { TGlucoraphanin under } \\
\text { blue light }\end{array}$ & 46 & & \\
\hline Selenium application & $\leftrightarrow$ & 127 & - & - & & \\
\hline
\end{tabular}

ヤIncrease; $\leftrightarrow \rightarrow$ no-effect; $\downarrow$ decrease 
Figure 1

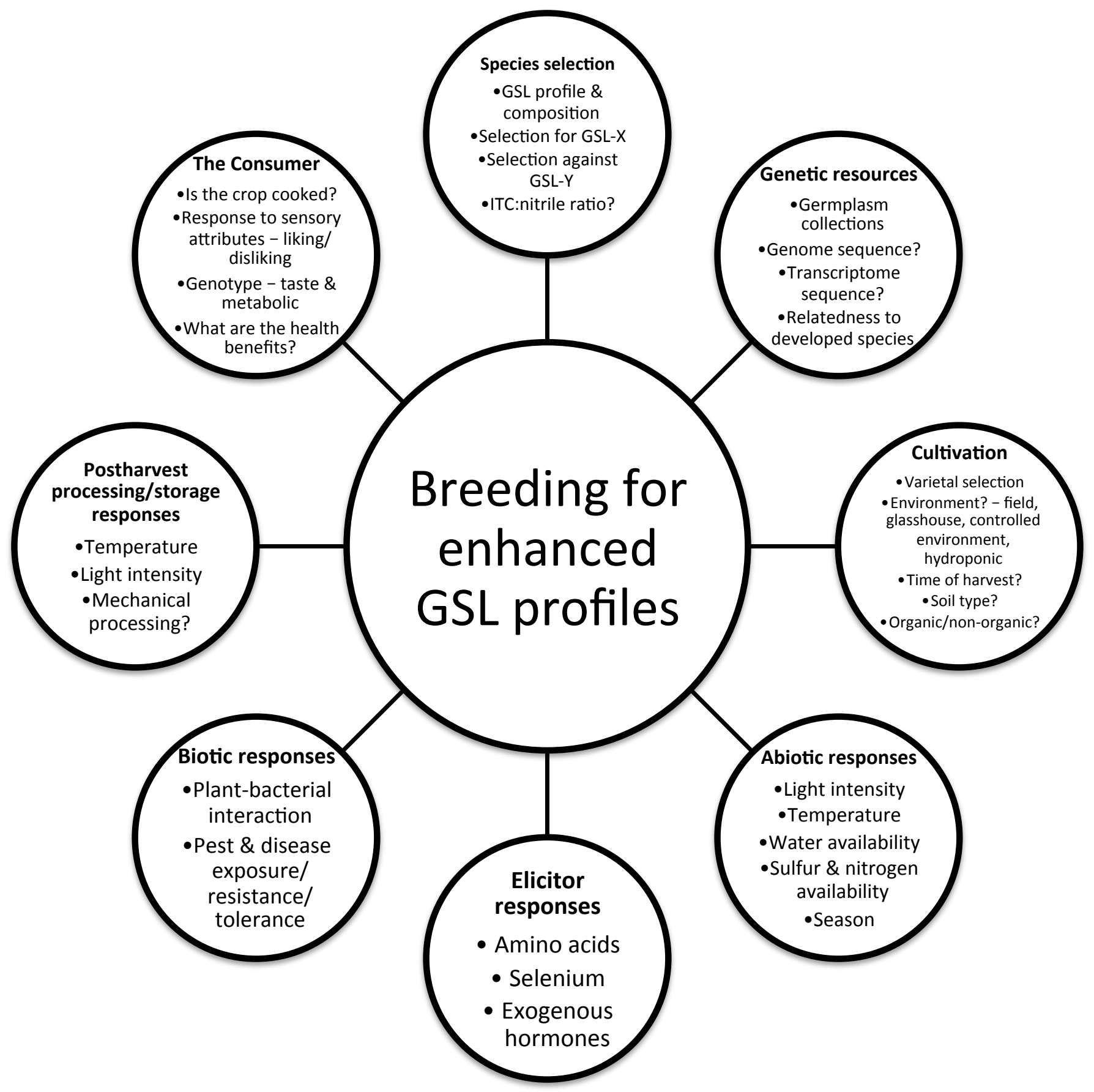


Figure 2.

\section{3,3'-diindolylmethane (DIM)}

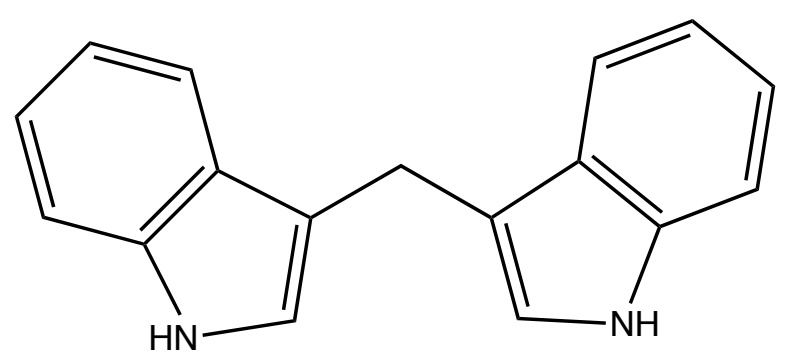

Sulforaphane (SFN)<smiles>CS(=O)CCCCN=C=S</smiles>

Phenethyl isothiocyanate (PEITC)<smiles>S=C=NCCc1ccccc1</smiles>

For Table of Contents Only

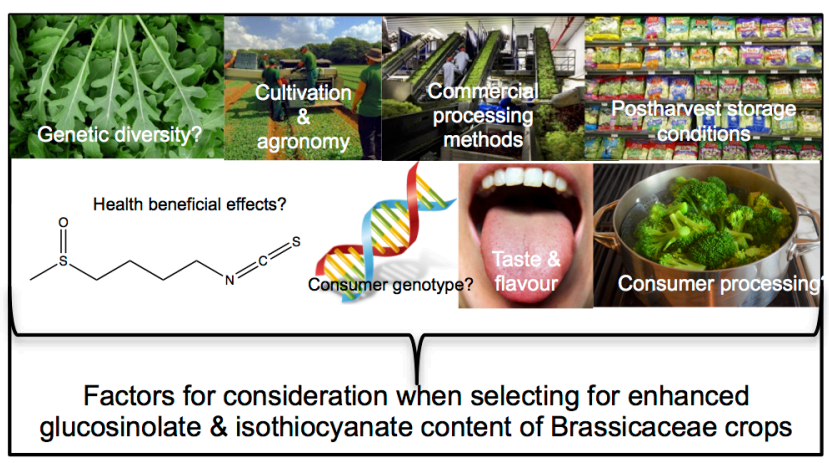

Indole-3-carbinol (I3C)<smiles>OCc1c[nH]c2ccccc12</smiles>

Benzyl isothiocyanate (BITC)<smiles>S=C=NCc1ccccc1</smiles> 